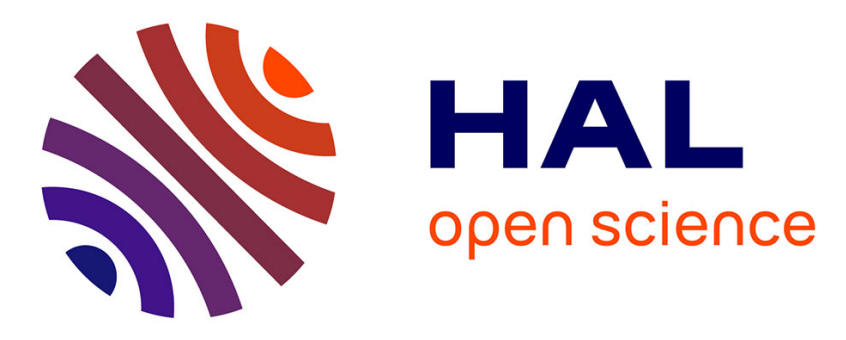

\title{
High-resolution structural and elemental analyses of calcium storage structures synthesized by the noble crayfish Astacus astacus
}

Gilles Luquet, Murielle Salomé, Andreas Ziegler, Céline Paris, Aline Percot, Yannicke Dauphin

\section{To cite this version:}

Gilles Luquet, Murielle Salomé, Andreas Ziegler, Céline Paris, Aline Percot, et al.. High-resolution structural and elemental analyses of calcium storage structures synthesized by the noble crayfish Astacus astacus. Journal of Structural Biology, 2016, 10.1016/j.jsb.2016.09.001 . hal-01373791

\section{HAL Id: hal-01373791 \\ https://hal.sorbonne-universite.fr/hal-01373791}

Submitted on 29 Sep 2016

HAL is a multi-disciplinary open access archive for the deposit and dissemination of scientific research documents, whether they are published or not. The documents may come from teaching and research institutions in France or abroad, or from public or private research centers.
L'archive ouverte pluridisciplinaire HAL, est destinée au dépôt et à la diffusion de documents scientifiques de niveau recherche, publiés ou non, émanant des établissements d'enseignement et de recherche français ou étrangers, des laboratoires publics ou privés. 


\section{High-resolution structural and elemental analyses of calcium storage structures} synthesized by the noble crayfish Astacus astacus

Gilles Luquet $^{\mathrm{a}, \mathrm{b}^{*}}$, Murielle Salomé ${ }^{\mathrm{c}}$, Andreas Ziegler ${ }^{\mathrm{d}}$, Céline Paris ${ }^{\mathrm{a}, \mathrm{e}}$, Aline Percot $^{\mathrm{a}, \mathrm{e}}$, Yannicke Dauphin ${ }^{\mathrm{a}, \mathrm{f}}$

${ }^{\text {a }}$ Sorbonne Universités, Paris, France

${ }^{\mathrm{b}}$ UMR BOREA, Biologie des Organismes et des Ecosystèmes Aquatiques, UMR

MNHN/CNRS 7208/UPMC/UCN/UA/IRD 207, Muséum National d'Histoire Naturelle, 75005 Paris, France

${ }^{\mathrm{c}}$ ID21, European Synchrotron Radiation Facility, 38000 Grenoble, France

${ }^{\mathrm{d}}$ Central Facility for Electron Microscopy, University of Ulm, 89069 Ulm, Germany

${ }^{\text {e }}$ UMR MONARIS, De la Molécule aux Nano-Objets: Réactivité, Interactions et Spectroscopies, UMR 8233 CNRS-Université Pierre et Marie Curie, 75005 Paris, France ${ }^{\mathrm{f}}$ Institut de Systématique, Evolution, Biodiversité, Muséum National d'Histoire Naturelle, 75005 Paris, France

*Corresponding author:

Phone: +33 1407936 23; E-mail address: gluquet@mnhn.fr (G. Luquet)

Keywords: Amorphous calcium carbonate, Amorphous calcium phosphate, Biomineralization, Calcium storage, Crustacea, Phosphorus 


\section{ABSTRACT}

During premolt, crayfish develop deposits of calcium ions, called gastroliths, in their stomach wall. The stored calcium is used for the calcification of parts of the skeleton regularly renewed for allowing growth. Structural and molecular analyses of gastroliths have been primarily performed on three crayfish species, Orconectes virilis, Procambarus clarkii, and more recently, Cherax quadricarinatus. We have performed high-resolution analyses of gastroliths from the native noble crayfish, Astacus astacus, focusing on the microstructure, the mineralogical and elemental composition and distribution in a comparative perspective. Field emission scanning electron microscopy (FESEM) and atomic force microscopy (AFM) observations showed a classical layered microstructure composed of 200-nm diameter granules aligned along fibers. These granules are themselves composed of agglomerated nanogranules of $50 \mathrm{~nm}$-mean diameters. Denser regions of bigger fused granules are also present. Micro-Raman spectroscopy show that if A. astacus gastroliths, similarly to the other analyzed gastroliths, are mainly composed of amorphous calcium carbonate (ACC), they are also rich in amorphous calcium phosphate (ACP). The presence of a carotenoid pigment is also observed in A. astacus gastrolith contrary to C. quadricarinatus. Energy-dispersive X-ray spectroscopy (EDX) analyses demonstrate the presence of minor elements such as $\mathrm{Mg}, \mathrm{Sr}, \mathrm{Si}$ and $\mathrm{P}$. The distribution of this last element is particularly heterogeneous. X-ray absorption near edge structure spectroscopy (XANES) reveals an alternation of layers more or less rich in phosphorus evidenced in the mineral phase as well as in the organic matrix in different molecular forms. Putative functions of the different P-comprising molecules are discussed.

\section{Introduction}

Biominerals are nanostructured composites resulting from an interplay between two phases: a mineral phase composed of precipitated mineral ions and an organic phase forming a 3D network and controlling, simultaneously or posteriorly to its elaboration, the crystallization process of these ions (Lowenstam and Weiner, 1989; Mann, 2001; Simkiss and Wilbur, 1989). This organic control is exerted over the composition and polymorph of the mineral, over the initiation, activation and inhibition of the precipitation process and over the growth and morphology of the biomineral. Besides the two main categories of chemical compounds, some elements have been evidenced associated with one or the two phases, but their function is not well deciphered for most of them. 
The main elements studied so far in invertebrate biominerals are metallic elements such as $\mathrm{Ca}, \mathrm{Mg}, \mathrm{Na}, \mathrm{Al}, \mathrm{K}, \mathrm{Fe}, \mathrm{Sr}, \mathrm{Ba}$ and metalloids like Si and B (e.g. Cusack and Freer, 2008; Lowenstam and Weiner, 1989; Mann, 2001; Simkiss and Wilbur, 1989; Weiner and Dove, 2003). Among the non-metal elements, Cl, S and P have been evidenced. Some recent works on invertebrate biominerals have focused on S (Cuif et al., 2003, 2008; Cusack et al., 2008; Dauphin et al., 2003, 2005; Luquet et al., 2016; Rousseau et al., 2009; Zhang et al., 2011). Phosphorus (P), very widespread and important in biology, was far from being commonly studied per se in the biomineralization field even if some recent works have evidenced the presence of phosphorylated molecules, mainly in crustaceans (e.g. Akiva-Tal et al., 2011; Bentov et al., 2010; Habraken et al., 2015; Luquet et al., 2016; Reeder et al., 2013; Reid et al., 2012; Sato et al., 2011).

Nevertheless, it is well known that if the main mineral used by invertebrates for hardening their skeleton is calcium carbonate, numerous other minerals are also found, notably phosphate and silica-based minerals (Cusack and Freer, 2008; Knoll, 2003; Lowenstam, 1972; Lowenstam and Weiner, 1989; Murdock and Donohue, 2011; Simkiss and Wilbur, 1989). For example, Linguliformae, subphylum of the phylum Brachiopoda, constitutes a group of invertebrate species, the shell of which is made up of francolite, a carbonated apatite (Cusack and Freer, 2008; Luo et al., 2015; Rudwick, 1970; Williams et al., 1994).

Moreover, it becomes more and more evident that most of the biominerals are a composite of several minerals. Notably phosphate minerals have been shown as coexisting with calcium carbonate in the skeleton of many non-chordate phyla (Lowenstam, 1972). As an example, amorphous calcium phosphate, ferrihydrite, lepidocrocite, magnetite and dahlite or francolite are minerals found in the radular teeth of chitons (Lowenstam, 1967; Lowenstam and Weiner, 1985).

In crustaceans, the barnacles of the genus Ibla (Cirripedia, Crustacea) have skeleton plates fully composed of carbonate apatite (Lowenstam and Weiner, 1992; Reid et al., 2012), whereas all other Cirripedia have a calcitic skeleton.

On the other hand, the presence of calcium phosphate, notably in the form of amorphous calcium phosphate (ACP) and carbonate apatite (CAP), in addition to calcium carbonate $\left(\mathrm{CaCO}_{3}\right)$, as amorphous calcium carbonate (ACC) and calcite, is common in the exoskeleton of decapods and isopods (Becker et al., 2005; Boßelmann et al., 2007; Fabritius et al., 2012; Greenaway, 1985; Grunenfelder et al., 2014; Hild et al., 2008, 2009; Kunkel, 2013; Levi-Kalisman et al., 2002; Luquet, 2012; Neues et al., 2007; Soejoko and Tjia, 2003; 
Vijayan and Diwan, 1996). Calcium phosphate has also been evidenced in the cuticle of peculiar limbs of stomatopods: the smashing limb of the mantis shrimp, Gonodactylus chiragra (Currey et al., 1982) and the hammer-like dactyl club of the peacock mantis shrimp, Odontodactylus scyllarus (Weaver et al., 2012). More recently, calcium phosphate has been evidenced as component of crustacean teeth: as ACP and fluorapatite in crayfish mandibles (Bentov et al., 2012) and as ACP in incisors of terrestrial isopods (Huber et al., 2014).

On the other hand, it is known for a long time that, in addition to the carboxylic groups of acidic amino acids or acidic monosaccharides, organic molecules can interfere with calcium ions thanks to particular groups added to proteins or sugars during maturation processes (Mann, 1988, 2001; Williams, 1976). Phosphorylations can constitute such important posttranslational modifications interacting with calcification processes (George and Veiss, 2008; Hecker et al., 2003; Inoue et al., 2001, 2004; Shechter et al., 2008b).

The presence of phosphorus in gastrolith is known since the work of Travis on Orconectes virilis (Travis, 1960, 1963). In this species, the amount of phosphorus was globally estimated to $1.6 \%$, a relative high content for a biogenic carbonate. Nevertheless nothing was clear as for the mineral or organic localization of phosphorus.

The presence and distribution of $\mathrm{P}$ were recently determined in Cherax quadricarinatus gastroliths in organic molecules as well as in the mineral phase as ACP (Luquet et al., 2016; Reeder et al., 2013). Phosphorylated proteins have been characterized and hypothesized as playing a role in Cherax gastrolith ACC stabilization (Bentov et al., 2010; Glazer and Sagi, 2012; Glazer et al., 2010; Shechter et al., 2008b). Small phosphorylated metabolites of the glycolytic pathway have also been evidenced by Nuclear Magnetic Resonance (NMR) and thought to play an interacting role between matrix proteins and calcium ions forming complexes preventing the crystallization of $\mathrm{CaCO}_{3}$ (Akiva-Tal et al., 2011; Sato et al., 2011).

In a recent paper (Luquet et al., 2016), in addition to Raman analyses, we have performed elemental analyses on Cherax quadricarinatus gastrolith by Energy Dispersive Xray spectroscopy coupled to Scanning Electron Microscopy (SEM-EDX) and X-ray

Absorption Near Edge Structure spectroscopy (XANES) focusing on S. S is present mainly as sulfated sugars and as S-bearing amino acids. Sulfite, sulfoxide and sulfonate were also detected as a minor contribution. Phosphorus is also present and heterogeneously distributed. Raman analyses suggest that ACP is present besides ACC and maybe also calcite.

In this report, we carried out the study of gastroliths from the native European crayfish, Astacus astacus (Pancrustacea, Decapoda, Astacoidea, Astacidae), a species classified as vulnerable (VU; IUCN, 2012), focusing on the microstructure and the elemental composition 
and distribution in a comparative perspective.

The structure was analyzed by light microscopy, Field Emission Scanning Electron Microscopy (FESEM) and Atomic Force Microcopy (AFM), which allowed observations from the macrolevel until the nanolevel. Then maps and spectra were obtained by Raman spectroscopy for analyzing the mineral composition and distribution.

SEM-EDX allowed general analyses of the composition in selected elements, minor or not, generally encountered in biominerals. The results obtained led to focus on the P element, by determining, thanks to EDX and XANES spectroscopy, not only its spatial-temporal distribution but also the chemical nature of the components comprising phosphorus. Finally, hypotheses were formulated as to the putative functions of these phosphatic molecules found both in the mineral and the organic phases.

\section{Material and Methods}

\subsection{Gastrolith sample preparation}

Astacus astacus and Cherax quadricarinatus are two freshwater crayfish (Decapoda, Pleocyemata) but A. astacus is a member of the Astacoidea family and Astacidae family whereas $C$. quadricarinatus belongs to the Parastacoidea superfamily and Parastacidae family.

Native noble freshwater crayfish, Astacus astacus, were captured using baited traps in ponds located near Dijon, France. They were then reared in large holding tanks filled with continuously aerated tap water until ecdysis, period of the molting cycle where gastroliths are at their maximum size. Immediately following ecdysis, animals were sacrificed by freezing and gastroliths extracted. Cherax quadricarinatus gastroliths were obtained from a rearing located in Chile, as previously described (Luquet et al., 2016).

After extraction, gastroliths were immersed in $10 \%(\mathrm{v} / \mathrm{v}) \mathrm{NaClO}, 6$ hours, to remove superficial organic contaminants, as usually performed since the eighties (e.g. Constantz and Weiner, 1988; Lowenstam and Weiner, 1992; Mutvei, 1980) then rinsed several times with distilled water and kept at room temperature and dry air until used.

Sections of whole gastroliths in two halves were performed by using an electric microsaw. Sections are realized perpendicularly to the surface and symmetrically through the 
center of the flat circular basis of the semispherical gastrolith. Sections were polished or not as described for the different techniques.

Two organic matrix fractions were obtained after grounding gastroliths from A. astacus or $C$. quadricarinatus to a powder. This powder was decalcified during $24 \mathrm{~h}$ in cold acetic acid $(10 \% \mathrm{v} / \mathrm{v})$ at $4^{\circ} \mathrm{C}$. The solution was then centrifuged at $4^{\circ} \mathrm{C}$ during $30 \mathrm{~min}$ at $4000 \mathrm{~g}$. The supernatant containing the acetic acid-soluble organic matrix (SM) was filtered and concentrated with an Amicon ultrafiltration system (Millipore SAS, France) on an UltracelPL membrane (5-kDa cut-off; Millipore SAS, France). The pellet containing the insoluble matrix (IM) was carefully washed several times with ultrapure water. The SM and IM fractions, devoid of acetic acid, were lyophilized and kept at $4{ }^{\circ} \mathrm{C}$ until used.

\subsection{Light microscopy and FESEM (Field Emission Scanning Electron Microscopy) observations}

For light microscopy observations, gastroliths were used after extraction and washing. The two types of transverse sections obtained as described above were observed using a Nikon Eclipse E200 microscope or a Nikon SMZ800 binocular stereomicroscope.

For FESEM observations, gastroliths were cleaved in two halves and mounted on aluminum holders using self-adhesive carbon pads and conductive glue without any polishing. Samples were then rotary shadowed with $3.5-4 \mathrm{~nm}$ platinum at an angle of $45^{\circ}$ using a BAF 300 (BAL-TEC, Balzers, Liechtenstein). FESEM was performed on a Hitachi S5200 microscope at an acceleration voltage of $4 \mathrm{kV}$ and an emission current of $10 \mathrm{~mA}$. Gastroliths from 3 different specimens of A. astacus were observed and compared with gastroliths of 3 C. quadricarinatus specimens.

\subsection{Atomic force microscopy (AFM)}

Samples were studied using a Nanoscope IIIa Dimension 3100 scanning probe microscope (Digital Instruments-Veeco, CA) operating in tapping mode in air. The AFM tapping mode uses an oscillating tip at an amplitude of approximately several tens of nanometers when the tip is not in contact with the surface. Since the tip is no longer in permanent contact with the sample surface during the scanning motion, unwanted alterations can be avoided to a large extent. The resolution of tapping mode AFM is in the order of a few nanometers. 
Tip-sample force interactions cause changes in amplitude, phase and the resonance frequency of the oscillating cantilever. The spatial variation of the change can be presented in height (topography) or interaction (amplitude or phase) images that can be collected simultaneously. Phase Imaging is a powerful extension that provides nanometer-scale information about surface structure: it monitors the phase lag between the signal that drives the cantilever to oscillate and the cantilever oscillation output signal. Thus, contrast in phase images is due to differences in material properties. The phase lag is monitored while the topographic image is being taken so that images of topography and material properties are collected simultaneously. The amplitude AFM signal is related to the gradient of the topography as the tip scans over the sample surface. Fine morphological features are easily observed in amplitude and phase images.

Compared with SEM, AFM provides topographic direct height measurements and views of surface features since no coating is necessary. Compared with TEM, three-dimensional AFM images are obtained without difficult sample preparation and with a similar resolution.

Sample sections were polished using P1200, P2500, and P4000 HERMES water grinding papers and 3 and $1 \mu \mathrm{m}$ diamond polycrystalline suspensions (Buehler, France). To avoid analytical artifacts, no aluminum oxide suspension was used because previous analyses on mollusk shells and coral skeletons (person. unpublished results) have shown that, despite repeated ultrasonic cleanings, alumina is not removed from the surface. To remove putative contaminations due to the polishing step, sections were then etched with formic acid $10 \%$ or acetic acid $2 \%$ for $5 \mathrm{sec}$, which does not create artifacts.

\subsection{Micro-Raman spectroscopy analyses}

The Raman spectra were recorded using a Horiba Jobin Yvon LabRam HR 800 spectrometer equipped with edge filters, a 600 lines/mm grating and a Peltier cooled CCD detector. Raman

scattering was collected via an Olympus microscope equipped with a 50X objective, allowing a laser spot size of about $3 \mu \mathrm{m}$. The excitation wavelength was the $532 \mathrm{~nm}$ line of an $\mathrm{Ar}^{+}$ Laser (Innova 90C, Coherent Inc.). The laser power at the sample was between 2 and $3 \mathrm{~mW}$, measured by a powermeter located at the exit of the microscope. The time of exposition was short, $3 \times 10 \mathrm{sec}$, which does not allow any transformation. 
This configuration led to a spectral resolution of about $2 \mathrm{~cm}^{-1}$, and calibration was checked with respect to the $520.7 \mathrm{~cm}^{-1}$ band of silicon. Typical recording times consisted of 3 accumulations of $10 \mathrm{sec}$.

For the mapping, spectra were recorded between 150 and $1950 \mathrm{~cm}^{-1}$. To investigate the spatial distribution of the minerals, the sample was moved by a computer-controlled stage. 2D-maps were performed on a 690 × $60 \mu \mathrm{m}$ surface for map A, on a 1200 x $60 \mu \mathrm{m}$ surface for map B and on a $700 \times 65 \mu \mathrm{m}$ surface for map C (with a step of $5 \times 5 \mathrm{~m}^{2}$ for each map). Maps were generated by calculating the ratio of the integrated intensities of two bands, at around $956 \mathrm{~cm}^{-1}\left(\mathrm{v}_{1} \mathrm{PO}_{4}{ }^{3-}\right)$ and $1080 \mathrm{~cm}^{-1}\left(\mathrm{v}_{1} \mathrm{CO}_{3}{ }^{2-}\right)$. Spectral acquisitions, baseline subtractions and map generations were managed by the LabSpec software (Horiba Jobin Yvon). The color scales are similar for Figures $6 \mathrm{~A}$ and $\mathrm{B}$ but different for Fig. $6 \mathrm{C}$ because of the homogenous distribution of one mineral, ACC, within this late storage region. The same scale would have led to a complete dark image (similar to the a areas on Figs. 6A and B).

\subsection{Electron microprobe analyses (EDX)}

A Zeiss DSM 962 SEM (Carl Zeiss Microscopy Gmbh, Oberkochen, Germany) equipped with an EDAX Falcon X-ray detector system (EDAX Business Unit, AMETEK GmbH, Wiesbaden, Germany) with a $10 \mathrm{~mm}^{2}$ SUTW window was used for energy-dispersive X-ray spectroscopy (EDX).

The samples (half-gastroliths) were mounted on a $45 \mathrm{~mm}$-diameter custom made device and polished to a mirror finish using a series of silicon carbide paper (Struers Gmbh, Willich, Germany) and $100 \%$ methanol instead of water to prevent dissolution of amorphous mineral phases.

Spectral maps were recorded from polished air-dried samples coated with a $10 \mathrm{~nm}$-thick layer of carbon at an acceleration voltage of $20 \mathrm{kV}$ and count rates between 1000 and $2000 \mathrm{~s}^{-}$

1 . Accumulated spectra from specific sites of interest and line scans of molar ratios (binning $5 \times 5$ pixels) were built from these maps employing Genesis software (EDAX).

Note that the device used only allows obtaining maps of $10-\mathrm{mm}^{2}$ maximum size, therefore a set of successive analyses is required for covering the whole surface of a gastrolith crosssection. Thus, the complete surface image shown in Fig. 4 is obtained by juxtaposition of 4 pictures.

\subsection{Micro-XANES (X-ray Absorption Near Edge Structure) spectroscopy analyses}


The work was carried out at the ID21 X-ray micro-spectroscopy beamline of the European Synchrotron Radiation Facility (ESRF, Grenoble, France) using the Scanning X-ray Microscope. The beam was focused by a fixed-curvature Kirkpatrick-Baez mirrors system down to a submicron X-ray probe. The micro-probe was $0.3 \times 0.6 \mu \mathrm{m}^{2}$ (vertical x horizontal size) with $10^{10}$ photons/s. An energy-dispersive Silicon Drift Diode (Bruker, Germany) with a collimated active area of $80 \mathrm{~mm}^{2}$ and equipped with a thin polymer window was used to collect the X-ray fluorescence (XRF) photons. An energy range between 2 and $7 \mathrm{keV}$ is available at ID21, which gives access to the K-edge of phosphorus at $2.145 \mathrm{keV}$. The XANES energy scan at the P K-edge was achieved using a fixed-exit double-crystal Si(111) monochromator (Kohzu, Japan) located upstream the microscope. XANES spectra were acquired between $2.13 \mathrm{keV}$ and $2.2 \mathrm{keV}$ with $0.2 \mathrm{eV}$ steps. This experiment required the $\mathrm{X}$-ray microscope to be operated under vacuum to avoid the strong absorption of the phosphorus emission lines by air.

Although the primary beam energy was set around that of the P K-edge energy region, elements with absorption edges at lower energies were also subject to excitation and emission of fluorescence photons, and could therefore be determined. Thus, micro-fluorescence element maps of $\mathrm{Sr}, \mathrm{Mg}, \mathrm{Na}, \mathrm{Al}$ were obtained simultaneously with the P maps. Elemental peaks deconvolution was performed using the data analysis tool PyMCA (Solé et al., 2007).

The XANES spectra of all phosphorus samples used as control in this study have white line peak energies between 2152.69 and $2152.89 \mathrm{eV}$ (Brandes et al., 2007). "This peak results from the excitation of an electron from an $1 \mathrm{~s}$ inner orbital to a higher-energy $t *_{2}$ orbital as a result of interaction with an X-ray. Subsequent decay of higher-energy electrons to unoccupied 1s orbitals releases photons, which are counted by the SDD detector" (Ingall et al., 2011). All phosphorus minerals measured in this study contained phosphorus in the $+V$ oxidation state. Although all white line peaks were found within the above energy range, systematic differences between mineral and organic samples were found.

For organic matrix analyses, samples were obtained as described in Materials and Methods. For in situ mapping and punctual analyses, gastrolith samples were cut in two halves and polished to a mirror finish using a series of silicon carbide paper (Struers Gmbh, Willich, Germany). They were then glued on a specific support for XANES analysis.

All the chemical compounds used as control originates from Sigma-Aldrich (France) except for ACP. The ACP spectrum data used for performing the fit analyses were kindly provided by Kim and colleagues (Kim et al., 2015). This spectrum was obtained on the same ID21 beamline at the ESRF of Grenoble. Other reference spectra of phosphorylated organic or 
mineral compounds were obtained similarly on the ID21 beamline at the ESRF of Grenoble (Giguet-Covex et al., 2013; Rivard et al., 2015).

XANES spectra were normalized and analyzed with the ATHENA program of the IFFEFIT software package (Ravel and Newville, 2005).

\section{Results}

\subsection{Light and FESEM observations}

The paired gastroliths extracted from an A. astacus specimen exhibit a classical hemispherical structure observed in crayfish, with a convex growing side in close contact with the calcifying epithelium (Fig. 1A) and a flat side (Fig. 1B) corresponding to the beginning of the calcium accumulation. The storage process occurs in between the stomach epithelium (in two specific discoidal areas) and a non-mineralized cuticle underlying this epithelium in the stomach. The inner view of a freshly extracted gastrolith shows the presence of a blue coloration (Figs. 1A and B). On a polished surface of a gastrolith cross-section (Fig. 1C), a concentric layered pattern is well visible, as well as striations perpendicular to these layers in the middle and late storage regions. After complete acidic decalcification, the 3-dimensionnal network of chitin-protein fibers remains (Fig. 1D), retaining the original shape of the gastrolith probably thanks to protein bridges linking the fibers as demonstrated for $C$. quadricarinatus gastroliths (Thormann et al., 2012). This translucent structure exhibits an orange color due to the reaction of the inner blue pigment with acetic acid (Luquet et al., 2013).

FESEM micrographs (Figs. 2A.1 and A.2) clearly show that the inner structure is not homogeneous since granular regions alternate with denser regions.

In Fig. 2, insert indicates two regions where observations were made showing two different organizations. In the early storage A region (Fig. 2A.1 and A.2), the structure appears regularly layered with irregular granules more or less fused, probably aligned along fibers (not clearly visible here). Note that Fig. 2A.2 shows an organization recalling the plywood structure of the cuticle (Bouligand, 1972). The late storage B region exhibits an alternation of two structurally different zones, more vertically distributed (Fig. 2B.1): zones of free granules and zones of larger fused granules. Fig. 2B.2 shows a transition zone between a fused granules area, on the left, and a free granules area, on the right. 
The denser regions (Figs. 2C.1 and C.2) are due to the fusion of granules (which appear flattened after fracturing), each one is itself the result of the fusion of smaller nanogranules.

The area shown in Figs. 2D.1 and D.2 corresponds to a free granules region. These rounded granules of regular size (from 150 to 200-nm diameter), linked by fibers of supposed protein-chitin chemical nature (Fig. 2D.2, arrows), are themselves composed of the agglomeration of the same small spheres comprising the larger fused granules. They are more visible in Fig. 3F, which is a magnification of the area delineated in Fig. 2D.2.

The morphology and size of these spherules (from 50-nm for the smallest spheres until 200-nm diameter for the larger composed granules) are in accordance with mineralized structures composed of an amorphous mineral (Bentov et al., 2010; Habraken et al., 2015; Luquet et al., 2013, 2016). Note that the fused granules have bigger sizes, from $300 \mathrm{~nm}$ until $500 \mathrm{~nm}$.

Spaces are visible in the two different regions, in between free or fused granules, in accordance with the porosity of the structure and the high degree of hydration of an amorphous polymorph. White small spots also appear in most images, which are crosssections of fibers.

It is to notice that, after comparative obseryations between 3 specimens of $A$. astacus and $C$. quaricarinatus, it appears that the presence and distribution of the fused granules and free granules regions are not regular. They appear randomly and vertically distributed in some gastroliths (as visible here in Fig. 2B.1) and regularly and alternately distributed as concentric layers (as shown in Fig. 2 A.1) in other samples whatever the species.

\subsection{AFM observations}

The layered structure visible at a macroscopic level on light images (Fig. 1.C) and at a microscopic level in FESEM (Fig. 2) appears in AFM images (Fig. 3A.1, height image; dotted lines showing parallel layers). It results of the alignment of granules along/around fibers (not visible here), as shown for gastroliths of other species (Travis, 1963; Glazer and Sagi, 2012; Luquet et al., 2016).

The phase contrast images shown in Figs. 3.B, 3.C, 3E and 3G.2 reveal that these granules are less spherical, more irregular than seen in FESEM at lower magnification (Fig. 2). Note that, whatever the region of the gastrolith observed (Figs. 3A, 3B and 3E: early 
storage period, Fig. 3C: intermediate storage period, Fig. 3D: late storage period), a similar nanogranular structure is present.

The phase contrast images (Fig. 3E, arrows) show clearly the presence of nanofibers among the spherules, which likely correspond to the chitin-protein fibers comprising the organic network. Note that their light appearance suggests that they could be wrapped by a mineral sheath as shown for the chitin-protein fibers in the carapace of the lobster Homarus americanus (Romano et al., 2007).

The nanostructure of the spherules is better visible at high magnification (Fig. 3F for a FESEM observation and Figs. 3B, D and E for AFM observations). The big spherules of around 200-nm diameter (within circles in Fig. 3C) seem to be the result of aggregation of single granules of around 50-nm diameter, well visible in Fig. 3E

Granules appear in phase contrast images as light irregular spherules with some darker zones visible on phase images (Fig. 3B, C and D). Considering that hard material have generally a light aspect in AFM, the darker regions could correspond to soft material, organic matter or amorphous mineral (Haugstad, 2012; Mittal and Matsko, 2012).

\subsection{Elemental composition analysis}

EDX maps of the same cross-section of a gastrolith have been obtained for elements selected from the spectra obtained (Fig. 5C): O, Ca Mg, Si, Sr, P (Fig. 4). Elemental distribution seems heterogeneous for most of them, more particularly for $\mathrm{Mg}$ and $\mathrm{P}$. Two layers appear particularly enriched in $\mathrm{Mg}$. P exhibits a layered distribution with an alternate richness from the beginning of the storage until the middle of the gastrolith, corresponding to the first and second regions of the gastrolith as described by Travis (1963). Then, a relatively homogeneous distribution is observed until the end of the storage (convex side). The two Mgrich layers are also rich in $\mathrm{P}$ at the limit between the $\mathrm{P}$-rich and the $\mathrm{P}$-poor regions. A subdivision of thick layers in thinner ones is also well visible in the P map.

For a better understanding of the topographical relationships between chemical elements, a profile has been done along a transect line a-b shown in Fig. 5A. The side "a" corresponds to the beginning of the storage, " $b$ " to the end of the storage.

Relative amounts (molar ratio in \%) for the 5 following elements, $\mathrm{Ca}, \mathrm{P}, \mathrm{Sr}, \mathrm{Mg}$ and $\mathrm{S}$, have been evaluated along the transect line (Fig. 5B). 
In the curves obtained (Fig. 5B), the mean values for strontium, magnesium and sulfur molar ratios are centered on 5\%, reaching rarely $8 \%$. Note small elevations for $\mathrm{Mg}$ at the level of the two Mg-rich layers (orange curve, asterisks) and some variations of $\mathrm{Sr}$ in different points of the transect line independently of the variations of $\mathrm{P}$ or other elements. The rate of $\mathrm{S}$ from 0 to $1 \%$ (raising rarely $2 \%$ ) is almost negligible.

On the contrary, the levels of $\mathrm{Ca}$ and $\mathrm{P}$ exhibit important variations. The $\mathrm{Ca}$ level varies by $30 \%$ (between 90 and 60\%). As for P, high variations are observed, between $5 \%$ for the lower molar ratio obtained until $30 \%$ for the highest one. Due to the low variations of the other elements analyzed, the variations of $\mathrm{Ca}$ and $\mathrm{P}$, the two main elements, are correlative, depending of two different regions defined by the amount of $\mathrm{P}$.

Regarding the distribution of $\mathrm{P}$, two regions can be clearly determined: the first one, which corresponds to the early until the middle premolt period, is a P-rich region with an alternation of large P-rich layers, with a molar ratio reaching $30 \%$ for the richest layers and with layers with P molar ratio values between 18 to $20 \%$. A second region is defined by a lower P level, which furthermore decreases (from a to b) from around 15 to $5 \%$.

The general spectra (Fig. 5C) obtained from two areas (see their localization in Fig. 5A) show a similar composition for the main elements detected but relative variations of the different elements detected ( $\mathrm{S}$ has been neglected). For area 1, we obtained as mean molar ratios, in \%: $\mathrm{Mg} 2.85, \mathrm{Sr} 1.31, \mathrm{P} 12.59, \mathrm{Ca}$ 83.15. For area 2: $\mathrm{Mg} 6.68, \mathrm{Sr} 1.74, \mathrm{P} 31.87, \mathrm{Ca}$ 59.70. The most important variation concerns $\mathrm{P}$, which is in accordance with the location of area 1 within the $\mathrm{P}$-poor region and area 2 within the $\mathrm{P}$-rich region. The $\mathrm{Ca} / \mathrm{P}$ ratio varies from 6.6 for area 1 to 1.87 for area 2 , which in both cases are high values for a biogenic carbonate. Note also a slight increase of the $\mathrm{Mg}$ value in area 2 in accordance with the presence of two Mg-rich layers in this area as visible in Fig. 4 (Mg map). All these observations are also in agreement with the molar ratios spectra variations analyzed above. Square 1 localization corresponds to the left of the spectra, square 2 to the middle region of the spectra with the two strong $\mathrm{P}$ peaks and two minor $\mathrm{Mg}$ peaks (Fig. 5B; asterisks on the $\mathrm{Mg}$ spectrum).

\subsection{Micro-Raman spectroscopy analyses}

Raman analyses were performed in situ on some spots of a gastrolith cross-section as well as by mapping some regions. As all the punctual spectra obtained (as shown in Fig. 7) revealed the presence of a peak at around $1080 \mathrm{~cm}^{-1}$ characteristic of carbonate ions (Urmos et al., 1991), and a broad peak at around $960 \mathrm{~cm}^{-1}$ characteristic of the presence of phosphate 
ions (Khan et al., 2013; Sauer et al., 1994), we decided to perform Raman maps by calculating the ratio of the surface band obtained at around $960 \mathrm{~cm}^{-1}$ and the surface band obtained at around $1085 \mathrm{~cm}^{-1}$ to evaluate the prominence of the two kind of calcium minerals detected, carbonated and phosphate.

Raman maps (Fig. 6) were performed on 3 different regions, which means different periods of calcium storage, Fig. 6A: beginning (early premolt), Fig. 6B: middle (intermediate premolt), Fig. 6C: end of the process (late premolt, until ecdysis). The color scale, from white (high ratio) to dark blue (low ratio), visible on the right of each map, is representative of the values obtained.

Dark color is in favor of a high level of phosphate whereas white color means a prominence of carbonate groups.

Map A (Fig. 6A; color scale: 0.5 to 3.7) corresponds to the flat region, which means the earlier storage region. This map exhibits an alternation of dark layers, synonymous of P-rich layers, and of more or less blue, until white layers, synonymous of a decrease of the phosphate content in favor of an increase of richness in carbonate ions. All the spectra obtained in this region (Fig. 7A, spectra a-blue, b-red and c-green; spectra at right: magnification of the left spectra from 900 to $1200 \mathrm{~cm}^{-1}$ ) show three broad bands at 718, 956 and $1080 \mathrm{~cm}^{-1}$. The two bands at 718 and $1080 \mathrm{~cm}^{-1}$ are characteristic of carbonate ions. The main band corresponds to the $\mathrm{A}_{\mathrm{g}}$ internal mode that derives from the symmetric stretching mode $v 1$ of carbonate ions (Urmos et al., 1991). This band, found in general at $1085 \mathrm{~cm}^{-1}$ for the crystallized polymorphs of $\mathrm{CaCO}_{3}$, is shifted towards $1080 \mathrm{~cm}^{-1}$, which is typical of the ACC polymorph (Wehrmeister et al., 2011). Similarly, the other band observed at $718 \mathrm{~cm}^{-1}$ (the internal $\mathrm{E}_{\mathrm{g}}$ mode corresponding to the in-plane bending $\mathrm{v}_{4}$ mode of calcite carbonate ions), which appears small and wide, is also characteristic of ACC. The third band at $956 \mathrm{~cm}^{-1}$ $\left(v_{1} \mathrm{PO}_{4}\right.$ vibration band, $\mathrm{P}=\mathrm{O}$ stretching mode; Sauer et al., 1994; Khan et al., 2013) is present on the three spectra, which means that phosphate ions are present everywhere. The small bands observed at around 425, 595 and $1006 \mathrm{~cm}^{-1}$ can also be attributed to the presence of phosphate ions (Khan et al., 2013; Sauer et al., 1994). Note that the two small bands at around 1270 and $1640-50 \mathrm{~cm}^{-1}$ are probably due to amide groups of proteins (Khan et al., 2013).

Nevertheless, the map indicates that some layers are mainly composed of calcium carbonate as ACC (light layers and red curve) whereas other layers are mainly composed of ACP (dark layers and blue spectra).

This is in accordance with the green (spot c) and blue (spot a) spectra (Fig. 7A), which 
show a diminution of the main band at $1080 \mathrm{~cm}^{-1}$ in favor of the band at $956 \mathrm{~cm}^{-1}$.

Map B (Fig. 6B; color scale: 0.5 to 7.5 ) could correspond to the transition zone in between the layered P-rich part of the gastrolith (bottom half of the map, with dark large layers) and the P-poor region of the gastrolith (top half of the map, with thin light layers). The corresponding spectra (Fig. 7B) confirm this color distribution with the blue spectrum where the band at $1082 \mathrm{~cm}^{-1}$ is of very low intensity, less than the band at $958 \mathrm{~cm}^{-1}$ (spot a in Fig. 6B, very dark blue layer) and the green spectrum (spot c in Fig. 6B, dark blue layer) which presents a similar intensity for the two main bands. These two spectra can be considered as showing the presence of a mix of ACC and ACP. The spectrum recorded in spot b (Fig. 7B, red spectrum) is typical of an ACC spectrum with, nevertheless, the presence of a small broad band at $958 \mathrm{~cm}^{-1}$.

Map C (Fig. 6C; color scale: -5 to 17 ), corresponding to the lately synthesized layers (i.e. during late premolt), presents an homogeneous color in spite of the extended color scale, which means that the mineral present is everywhere the same. This is confirmed by the three spectra (Fig. 7C) recorded in spots a, b and c on this map, which are similar to each other and to the red spectra in the Figs. 7A and B. All these spectra are typical of ACC. Nevertheless, we may observe that the position of the main carbonate ions bands is not similar for the 3 spectra (well visible in the magnification shown on the right side in Fig. 7C). The difference in between $1083 \mathrm{~cm}^{-1}, 1081 \mathrm{~cm}^{-1}$ and $1079 \mathrm{~cm}^{-1}$ could correspond to a difference of crystallinity degree of $\mathrm{CaCO}_{3}$, from poorly crystalline until amorphous, respectively (Wehrmeister et al., 2011).

On all the nine spectra presented on Fig. 7, three bands are visible at around $1156 \mathrm{~cm}^{-1}$, $1270 \mathrm{~cm}^{-1}$ and $1510 \mathrm{~cm}^{-1}$. These bands are characteristic of a carotene pigment (De Gelder et al., 2007). They appear more intense when the main mineral is ACC (red spectra). Note that the band at around $1006 \mathrm{~cm}^{-1}$, previously attributed to phosphate groups, can also be attributed to this carotenoid pigment.

\subsection{Micro-XANES P analyses}

Fig. 8 shows the XANES spectra obtained for standard organic samples (Fig. 8A; 1: Phytic acid, 2. Casein, 3. Glucose 6-P) and mineral samples (Fig. 8B; 4: Dibasic calcium phosphate, 5: Geological apatite, 6: Amorphous Calcium Phosphate) used to acquire reference spectra and allow fitting of the analyzed samples thanks to the ATHENA program of the IFFEFIT software. All the P samples exhibit a main peak around $2152 \mathrm{eV}$. Two 
characteristics differentiate the mineral and organic P-samples. All the mineral P samples exhibit a small shoulder at approximately $2157 \mathrm{eV}$ on the white line, whereas a regular peak is observed at this level for organic P samples. Furthermore the broad secondary peak centered around $2167 \mathrm{eV}$ is rather smooth for the organic samples and more structured, subdivided in two broad peaks, for the mineral samples as previously described (Brandes et al., 2007; Ingall et al., 2011).

Fig. 9 corresponds to the analysis of organic matrix extracted from gastroliths after decalcification and separated in two fractions depending on their solubility in the decalcifying solution used (10\% acetic acid). The SM fractions comprise the molecules soluble in acetic acid, the IM fraction the molecules insoluble in this solution. We used two different species for a comparison. We analyzed the SM and IM fractions obtained from the same Cherax quadricarinatus gastroliths extract (SM1 and IM1, Fig. 9A and C), the SM fraction from another Cherax quadricarinatus gastroliths extract (SM2, Fig. 9B), and the SM fraction from and Astacus astacus gastroliths extract (Fig. 9D). All the spectra obtained appear similar whatever the organic matrix fraction analyzed with a regular curve characteristic of organic samples. The spectra can be perfectly fitted with a reference spectrum of casein (shown for the SM fraction from C. quadricarinatus; Fig. 9B). This result only suggests that Phosphorus could be present as organic phosphate groups in a chemical environment similar to the one encountered in phosphate groups linked to Ser and Thr amino acids, as it is in casein.

Fig. 10A corresponds to the global X-ray fluorescence (XRF) spectrum summed over a whole X-ray micro-fluorescence map (Fig. 10B) and which shows a large P peak and secondary contributions from other excited elements ( $\mathrm{Na}, \mathrm{Mg}$ and $\mathrm{Al})$ as explained in Material and Methods.

The spatial distribution of $\mathrm{P}$ was obtained by micro-XRF mapping on a cross-section of an $A$. astacus gastrolith. Fig. 10B shows this spatial distribution, which appears heterogeneously distributed with an alternation of P-rich layers and layers where $\mathrm{P}$ is from low level (grey) until absent (black).

The spatial distribution of the other elements fluorescing in the same regions, $\mathrm{Al}, \mathrm{Mg}$, $\mathrm{Na}$, was also obtained (Fig. 10B; the distribution of Al, of very low level, is not shown). Their distribution does not seem correlated with each other. Na seems more abundant and heterogeneously distributed than Mg. Note that the sample used for XANES analysis is not the same than the sample used for EDX analysis so that the two Mg-rich layers observed in EDX do not seem a common feature of all the gastroliths. If $\mathrm{Al}$ and $\mathrm{Sr}$ contributions can also be evidenced, the $\mathrm{Al}$ and $\mathrm{Sr}$ spatial distributions can however not be accurately mapped 
because of their low signal (especially for Sr with regards to the background created by the strong P peak). P and Sr can hardly be deconvolved and the Sr map obtained mainly follows the $\mathrm{P}$ distribution (not shown).

Fig. 11A shows P XRF maps where 14 spots analyzed with micro-XANES are indicated. On the left map, three squares are drawn, which indicate three areas, the magnification of each one is shown on the right. On these areas, spots 7 to 14 are localized. Diagram showing the results of the linear combination fits calculated for the 14 selected spots is shown in Fig. 11B. Due to the layering growth process related to the organic matrix synthesis process, considered as synchronous in all the gastrolith disc, the composition within each layer should be everywhere the same.

Among the reference spectra, only 3 or 4 are enough for fitting the sample spectra. An example of fit is shown in Fig. 12. The results confirm that, whatever the layer analyzed, a mix of P-mineral and P-organic molecules is present. Regarding the spatial, correlated with the temporal, distribution of the P-components (from 14 to 1 in a chronological point of view), nothing clear can be deduced. Note that phosphate is not only present as ACP, as previously deduced from Raman analyses, but could also be found in a crystalline compound such as tricalcium phosphate (TCP), a vertebrate skeleton and teeth component (as suggested by the fit results presented on Fig.11B and the spectra shown on Fig. 12).

\section{Discussion}

Astacus astacus gastroliths have a hemispherical form and an inner structure mostly layered. Each layer is composed of parallel fibers of probable chitin-protein chemical nature along which are aligned nanogranules, as previously observed for other analyzed crayfish gastroliths such as Orconectes limosus and Cherax quadricarinatus (Luquet et al., 2013, 2016; Shechter et al., 2008a; Travis et al., 1960, 1963). A similar organization was also described by Habraken et al. (2015) for gastroliths of a crayfish, the genus and species of which are not named in the study, so that detailed comparisons are not possible.

FESEM and AFM pictures show that these nanogranules of around 50-nm diameter for the smallest ones can be subject to two levels of modifications. They can agglomerate to form bigger granules of size up to $200 \mathrm{~nm}$, which is in accordance with the two-step mode of growth previously evoked for other calcified biominerals (Cuif and Dauphin, 2005; Cuif et al., 2008) and described for C. quadricarinatus gastroliths (Luquet et al., 2016). A second 
possible modification process can be observed at the level of dark and dense regions composed of fused granules.

The denser regions are the result of the fusion of small granules resulting in bigger granules of size up to $500 \mathrm{~nm}$. There is no real distribution of free-spherules regions and fused big granules-regions. In some areas the spherules stop growing before they can fuse, while in other regions they grow until they fuse.

A similar mechanism was proposed for the sternal deposits of Porcellio scaber (Fabritius and Ziegler 2003). These analogous calcium deposits synthesized during each premolt by terrestrial isopods were shown as species-dependent (Ziegler and Miller, 1997; Ziegler et al., 2005). The authors suggested a relation between the evolution of isopods aquatic species towards terrestrialisation and the consequent need to store more and more calcium linked to the thickening of the cuticle. This kind of explanation cannot be applied to crayfish from an evolution point of view. One hypothesis is that the presence of such dense regions could be related to the possibility of storing more or less calcium depending of environmental factors, notably at the end of the storage period.

EDX analysis reveals, in A. astacus gastrolith, the presence of classical elements such as $\mathrm{Mg}, \mathrm{Sr}, \mathrm{S}, \mathrm{P}$ as observed in Cherax quadricarinatus (Luquet et al., 2016). Nevertheless, the amount of these elements remains low except for $\mathrm{P}$, which, furthermore, exhibits an interesting heterogeneous distribution. Indeed, if $\mathrm{P}$ seems present everywhere within gastroliths, half of the gastrolith (synthesized during early-middle premolt) exhibits thick Prich layers, whereas the second half of the gastrolith (middle and late premolt) is homogeneous with a lower and decreasing level of P.

The Raman mapping confirms the presence of these two regions differing by their richness in P. Contrary to C. quadricarinatus, only ACC and ACP seem present, calcite has not been evidenced. The Raman spectra are in accordance with these observations, with a more or less important band visible at $956-958 \mathrm{~cm}^{-1}$. This band is attributed to the presence of phosphate group ( $v 1 \mathrm{PO}_{4}$ vibration band; Khan et al., 2013) generally found at $960 \mathrm{~cm}^{-1}$ for HAP and other crystallized calcium phosphates. A slight shift of this band towards $956 \mathrm{~cm}^{-1}$ can be attributed both to the presence of ACP (Sauer et al., 1994; Soejoko and Tjia, 2003; Awonusi et al., 2007; Combes and Rey, 2010) as well as to organic phosphated compounds (Bentov et al., 2010). However, bands at the same position as those of ACP might also be due to disordered domains arising from the drying of surface hydrated layers of poorly crystalline apatite (Combes and Rey, 2010). In this sense, Soejoko and Tjia (2003) suggest that calcium 
phosphate, observed with ACC in the cuticle of the giant prawn Marcrobrachium rosenbergii, could be in the form of a mixture of amorphous and microcrystalline minerals.

As for the analogous isopods sternal plates, they also comprise ACC and ACP, which are suspected to be used for the mineralization of the exoskeleton in which calcite, ACC and ACP have been identified (Becker et al., 2005; Hild et al., 2008; Neues et al., 2007; Ziegler, 2003). Another particular example is the isopod Hynoliscus riparius, which possesses ACC-ACP deposits associated with bacteria in a posterior pair of organs called calcium bodies (Vittori et al., 2013).

Until now, the characterization of the P-comprising molecules in gastroliths, as well as in other crustacean storage structures, has been poorly undertaken. XANES analyses performed on A. astacus demonstrate that phosphorus is present in the two phases of these biominerals. In the mineral phase, $\mathrm{P}$ is found as $\mathrm{ACP}$, as demonstrated also by Raman analysis. It could also be present in a crystalline mineral as shown by the XANES fit analyses. In the organic phase, $\mathrm{P}$ is shown associated with phosphated molecules, putatively proteins, as suggested by the XANES results.

Moreover, it has been shown that $\mathrm{P}$ is present in each layer studied in the two phases, mineral and organic, in a different composition from one layer to the other, without understanding why.

What could be the functions of $\mathrm{P}$ observed in the different layers, which means in different molecules within the gastrolith? Is P only used for building the gastrolith? Is P reused after molting? Is it lost partly or completely during resorption of gastroliths, as is lost a part of the stored calcium ions? Several hypotheses can be advanced.

$\mathrm{P}$ can be a stored element used as phosphate ions for the postmolt mineralization of parts of the cuticle where ACP and CAP have been clearly evidenced in all the decapods studied so far. Nevertheless, nothing is known regarding the mineral composition of any crayfish.

It was previously observed that decapods, which do not develop gastroliths, can store, in other storage sites such as hepatopancreas or haemolymph, not only calcium and carbonate but also phosphate ions used for the mineralization of each new cuticle (Becker et al., 1974; Corrêa, 2002, 2009; Sparkes and Greenaway, 1984; Travis, 1955).

It has been evoked that the P/Ca ratio increases with the hardness of the cuticle (Currey et al., 1982), when $\mathrm{P}$ is under the form of a crystalline polymorph of calcium phosphate. It is why $\mathrm{P}$ is mainly localized in the exocuticle, the outer part of the cuticle. At the contrary, Huber et al. (2014) showed lower hardness and elastic modulus in ACP-rich regions in 
Porcellio scaber mandibles. So the presence of calcium carbonate as ACC and calcium phosphate as ACP within calcium storage structures could be seen as facilitating the rapid resorption of the stored calcium ions after ecdysis.

However, gastrolith ACP cannot be considered as a reservoir of phosphorus available for the crayfish carbonated apatite teeth, the mineralization of those occurs in premolt concomitantly with gastrolith formation (Bentov et al., 2012).

Another function, which can be attributed to phosphorus-containing molecules in gastroliths, is linked to the stabilization of the amorphous calcium carbonate polymorph, ACC. Regarding this biogenic ACC polymorph, whereas its geological counterpart is not found in the field because of its complete instability, it was previously suggested that specialized macromolecules (acidic proteins, phosphoproteins, sulfated glycoproteins) or ions such as magnesium or phosphate could contribute to the stabilization of biogenic ACC (Aizenberg et al., 1996, 2002; Raz et al., 2000, 2003; Addadi et al., 2003; Luquet and Marin 2004; Marin and Luquet, 2007).

Regarding the ACC phase stabilization found in gastroliths, the role of phosphate groups linked to proteins has been suggested (Bentov et al., 2010; Glazer and Sagi, 2012; Shechter et al., 2008a). It should be also noted that in vitro calcium carbonate precipitation experiments performed recently in presence of casein has led to the conclusion that casein, through its phosphate groups, can play important roles "as an effective stabilization agent for ACC" (Liu et al., 2012a) and "in directing growth and self-assembly of spherical ACC particles into ACC superstructures" (Liu et al., 2012b).

Furthermore, as previously pointed out, Sato et al. (2011) and Akiva-Tal et al. (2011), by using solid state NMR spectroscopy, demonstrated the presence of energy-rich phosphorylated components in the cuticle and gastroliths of Procambarus clarkii and Cherax quadricarinatus. They suggested their possible involvement in the inhibition of the transformation of ACC into a crystalline polymorph. Similarly, NMR analyses performed by Corrêa et al. $(2002,2009)$ revealed that amorphous mineral storage structures found in the hepatopancreas of the crab, Ucides cordatus, which are phosphate-rich granules containing mainly orthophosphate, but also pyrophosphate and glucose-6-phosphate, are possibly involved in the stabilization of calcium carbonate in amorphous form in the crab cuticle.

Light microscopy observations of natural or decalcified gastroliths of A. astacus show the presence of a blue-orange pigment. This pigment is identified as a carotenoid pigment by Raman spectroscopy. Any pigmentation was never observed in Cherax quadricarinatus gastrolith. Nevertheless, a previous paper (Luquet et al., 2009) reported the characterization of 
A2-crustacyanin as a component of the acetic acid soluble matrix of $C$. quadricarinatus gastroliths. This protein is one of the two monomers of a multimacromolecular carotenoprotein complex called Crustacyanin (Keen et al., 1991). Crustacyanin is an octamer of a heterodimer (A2-C1 or A1-C2) involved in the binding of the astaxanthin carotenoid (one molecule bound by monomer) resulting in the blue color of the carapace of decapod crustaceans. If only one subunit has been characterized so far among the Cherax gastrolith matrix proteins, explaining the absence of color of gastroliths in this species, we can suggest the presence, in A. astacus gastroliths, of one of the two pairs of crustacyanin subunits forming an heterodimer, the polymerization of which is necessary for the binding of the astaxanthin pigment.

The presence of such a pigment within a structure that is synthesized in a close compartment within the organism seems very strange. Nevertheless, it is to recall that the stomach is covered, on the lumen side, by a thin unmineralized cuticle in continuity with the outside cuticle. Both cuticles are synthesized by underlying epithelia (called hypodermis and stomach epithelium), which are also in continuity each other. As gastroliths are synthesized in two specialized areas by stomach epithelium cells analogous and homologous to hypodermis cells, genes encoding cuticular proteins could be activated both in the hypodermis and the stomach disc so that similar proteins could be components of both the outer cuticle and the gastrolith, as previously evoked (Glazer et al., 2015; Yudkovski et al., 2010). This could explain for example the presence of crustacyanin subunits in both the outside cuticle and the gastroliths resulting in the presence of a pigment within the gastroliths.

\section{Conclusion}

The microstructure of Astacus astacus gastrolith seems almost similar to any other gastrolith structure, from the macrolevel until the micrometer level. These calcium storage deposits are composed of a loose and permeable network of chitin-protein fibers, along which microspherules of mineral (of around 200-nm diameter) are aligned, forming granular regions which alternate with dense regions composed of fused granules, as observed in analogous isopods deposits. The distribution of these dense regions seems heterogeneous reflecting individual variations between $A$. astacus specimens as it is for Cherax quadricarinatus.

All the granules are the result of the agglomeration of single spherules of around 50-nm diameter composed of ACC and/or ACP. Contrary to C. quadricarinatus gastroliths, calcite is 
not detected anywhere in A. astacus gastrolith. Three levels of granules aggregation have been clearly shown for the first time in crayfish gastroliths.

The presence of a carotenoid pigment, probably astaxanthin, was also evidenced for the first time within a gastrolith. If its presence in such a structure is difficult to interpret, it could be related to a similar genetic synthesis process of both the cuticle and gastrolith matrices.

Finally, A. astacus gastroliths exhibit a high content of $\mathrm{P}$, higher than in $C$. quadricarinatus gastroliths, present in each layer in both the organic phase (mainly as phosphorylated groups) and the mineral phase (as ACP). Phosphorus reveals as an important, probably multifunctional, element in the mineralization process of Astacus astacus crayfish skeleton parts. It could be involved in the formation of the cuticle mineral phase (as ACP) and in both the precipitation and stabilization of $\mathrm{CaCO}_{3}$ as $\mathrm{ACC}$ in two kinds of calcified biominerals, gastrolith and cuticle, synthesized and partly or completely resorbed during each molting cycle.

Nevertheless, it remains to decipher the precise interaction of these P-molecules with mineral ions, from the nucleation step, the precipitation process until the stabilization of calcium carbonate under the amorphous polymorph, and this, in these two regularly renewed calcified biominerals synthesized by decapod crustaceans.

\section{Acknowledgments}

This study received a financial support from the MNHN, Paris, France through its ATM project funding system (ATM: Interactions Minéral-Vivant). This research work is part of an INSU-INTERRVIE project funded by the French National Center of Scientific Research (CNRS) for 2015. This work has also been made possible thanks to ESRF grants $\left(\mathrm{N}^{\circ}\right.$ LS-2371; ESRF, Grenoble, France).

\section{References}

Addadi, L., Raz, S., Weiner, S. 2003. Taking advantage of disorder: amorphous calcium carbonate and its role in biomineralization. Adv. Mater. 15, 959-970.

Aizenberg, J., Lambert, G., Addadi, L, Weiner, S. 1996. Stabilization of amorphous calcium carbonate by specialized macromolecules in biological and synthetic precipitates. Adv. Mater. 8, 222-226. 
Aizenberg, J., Lambert, G., Weiner, S., Addadi, L. 2002. Factors involved in the formation of amorphous and crystalline calcium carbonate: a study of an ascidian skeleton. J. Am. Chem. Soc. 124, 32-39.

Akiva-Tal, A., Kabaya, S., Balazs, Y.S., Glazer, L., Berman, A., Sagi, A., Schmidt, A. 2011. In situ molecular NMR picture of bioavailable calcium stabilized as amorphous $\mathrm{CaCO}_{3}$ biomineral in crayfish gastroliths. Proc. Natl. Acad. Sci. USA 108, 14763-14768.

Awonusi, A., Morris, M.D., Tecklenburg, M.M.J. 2007. Carbonate assignment and calibration in the Raman spectrum of apatite. Calcif. Tissue Int. 81, 46-52.

Becker, A., Ziegler, A., Epple, M. 2005. The mineral phase in the cuticles of two species of Crustacea consists of magnesium calcite, amorphous calcium carbonate, and amorphous calcium phosphate. Dalton Trans 1814-1820.

Becker, G.L., Chen, C.-H., Greenawalt, J.W., Lehninger, A.L. 1974. Calcium phosphate granules in the hepatopancreas of the blue crab Callinectes sapidus. J. Cell Biol. 61, 316326.

Bentov, S., Weil, S., Glazer, L., Sagi, A., Berman, A. 2010. Stabilization of amorphous calcium carbonate by phosphate rich organic matrix proteins and by single phosphoamino acids. J. Struct. Biol. 17, 207-215.

Bentov, S., Zaslansky, P, Al-Sawalmih, A, Masic, A, Fratzl, P, Sagi, A, Berman, A, Aichmayer, B. 2012. Enamel-like apatite crown covering amorphous mineral in a crayfish mandible. Nat. Commun. 3, 839.

Boßelmann, F., Romano, P., Fabritius, H., Raabe, D., Epple, M. 2007. The composition of the exoskeleton of two crustacea: The American lobster Homarus americanus and the edible crab Cancer pagurus. Thermochim. Acta 463, 65-68.

Bouligand, Y. 1972. Twisted fibrous arrangements in biological materials and cholesteric mesophases. Tissue Cell, 4, 189-217.

Brandes, J.A., Ingall, E., Paterson, D. 2007. Characterization of minerals and organic phosphorus species in marine sediments using soft X-ray fluorescence spectromicroscopy. Mar. Chem. 203, 250-265.

Combes, C., Rey, C. 2010. Amorphous calcium phosphates: synthesis, properties and uses in biomaterials. Acta Biomater. 6, 3362-3378.

Constantz, B., Weiner, S. 1988. Acidic macromolecules associated with the mineral phase of scleractinian coral skeletons. J. Exp. Zool. 248, 253-258. 
Corrêa J.D., Farina, M., Allodi, S. 2002. Cytoarchitectural features of Ucides cordatus (Crustacea Decapoda) hepatopancreas: structure and elemental composition of electrondense granules. Tissue Cell 34, 315-325.

Corrêa, J.D., Bruno, M.I., Allodi, S., Farina, M. 2009. Effects of H+ concentration on amorphous mineral granules: Structural stability and elemental mobilization. J. Struct. Biol. 166, 59-66.

Cuif, J.P., Dauphin Y. 2005. The two-step mode of growth in the scleractinian coral skeletons from the micrometre to the overall scale. J. Struct. Biol. 150, 319-331.

Cuif, J.P., Dauphin, Y., Doucet, J., Salomé, M., Susini, J. 2003. XANES mapping of organic sulfate in three scleractinan coral skeletons. Geochim. Cosmochim. Acta 67, 75-83.

Cuif, J.P., Dauphin, Y., Farré, B., Nehrke, G., Nouet, J. 2008. Distribution of sulfated polysaccharides within calcareous biominerals suggests a widely shared two-step crystallization process for the microstructural growth units. Mineral. Mag. 72, 233-237.

Currey, J.D., Nash, A., Bonfield, W. 1982. Calcified cuticle in the stomatopod smashing limb. J. Mater. Sci. 17, 1939-1944.

Cusack, M., Freer, A. 2008. Biomineralization: Elemental and organic influence in carbonate systems. Chem. Rev., 108, 4433-4454.

Cusack, M., Dauphin, Y., Cuif, J.P., Salomé, M., Freer, A., Yin, H. 2008. Micro-XANES mapping of sulfur and its association with magnesium and phosphorus in the shell of the brachiopod, Terebratulina retusa. Chem. Geol. 253, 172-179.

Dauphin, Y., Cuif, J.P., Doucet, J., Salomé, M., Susini, J., Williams, T. 2003. In situ chemical speciation of sulfur in calcitic biominerals and the simple prism concept. J. Struct. Biol. $142,272-280$.

Dauphin, Y., Cuif, J.P., Salomé, M., Susini, J. 2005. Speciation and distribution of sulfur in a mollusk shell as revealed by in situ maps using X-ray absorption near-edge structure (XANES) spectroscopy at the S K-edge. Am. Mineral. 90, 1748-1758.

De Gelder, J., De Gussem K., Vandsenabeele, P., Moens L. 2007. Reference database of Raman spectra of biological molecules. J. Raman Spectr. 38, 1133-1147.

Fabritius, H., Ziegler, A. 2003. Analysis of $\mathrm{CaCO}_{3}$ deposit formation and degradation during the molt cycle of the terrestrial isopod Porcellio scaber (Crustacea, Isopoda). J. Struct. Biol. 150, 190-199.

Fabritius, H., Balasundaram, E.S., Hild, S., Huemer, K., Raabe, D. 2012. Correlation of structure, composition and local mechanical properties in the dorsal carapace of the 
edible crab Cancer pagurus. Z. Kristallogr. Kristallgeom. Kristallphys. Kristallchem. 227, 766-776.

George, A., Veiss, A. 2008. Phosphorylated proteins and control over apatite nucleation, crystal growth and inhibition. Chem. Rev. 108, 4670-4693.

Giguet-Covex, C., Poulenard, J., Chalmin, E., Arnaud, F., Rivard, C., Jenny, J. P., Dorioz, J.M. 2013. XANES spectroscopy as a tool to trace phosphorus transformation during soil genesis and mountain ecosystem development from lake sediments. Geochim.

Cosmochim. Acta 118, 129-147.

Glazer, L., Sagi, A. 2012. On the involvement of proteins in the assembly of the crayfish gastrolith extracellular matrix. Invert. Rep. Dev. 56, 57-65.

Glazer, L., Shechter, A., Tom, M., Yudkovski, Y., Well, S., Aflalo, E.D., Pamuru, R.R., Khalaila, I., Bentov, S., Berman, A., Sagi, A. 2010. A protein involved in the assembly of an extracellular calcium storage matrix. J. Biol. Chem. 285, 12831-12839.

Glazer, L., Roth, Z., Weil, S., Aflalo, E.D., Khalaila, I., Sagi, A. 2015. Proteomic analysis of the crayfish gastrolith chitinous extracellular matrix reveals putative protein complexes and a central role for GAP 65. J. Proteomics 128, 333-343.

Greenaway, P. 1985. Calcium balance and molting in the Crustacea. Biol. Rev. 60, 425-454.

Grunenfelder, L.K., Herrera, S., Kisalius, D. 2014. Crustacean-derived biomimetic components and nanostructured composites. Small 16, 30207-30232.

Habraken W.J.E.M., Masic, A., Bertinetti, L., Al-Sawalmih, A., Glazer, L., Bentov, S., Fratzl, P., Sagi, A., Aichmayer, B., Berman, A. 2015. Layered growth of crayfish gastrolith: About the stability of amorphous calcium carbonate and role of additives. J. Struct. Biol. $189,28-36$.

Haugstad, G. 2012. Atomic Force Microscopy: Understanding basic modes and advanced applications. John Wiley and Sons, Hoboken, NJ, USA.

Hecker, A., Testenière, O., Marin, F., Luquet, G. 2003. Phosphorylation of serine residues is fundamental for the calcium binding ability of Orchestin, a soluble matrix protein from crustacean calcium storage structures. FEBS Lett. 535, 49-54.

Hild, S., Marti, O., Ziegler, A. 2008. Spatial distribution of calcite and amorphous calcium carbonate in the cuticle of the terrestrial crustaceans Porcellio scaber and Armadillidium vulgare. J. Struct. Biol. 163, 100-108.

Hild, S., Neues, F., Znidaršic, N., Štrus, J., Epple, M., Marti, O., Ziegler, A. 2009.

Ultrastructure and mineral distribution in the tergal cuticle of the terrestrial isopod Titanethes albus. Adaptations to a karst cave biotope. J. Struct. Biol. 168, 426-436. 
Huber, J., Fabritius, H.O., Griesshaber, E., Ziegler, A. 2014. Function-related adaptations of ultrastructure, mineral phase distribution and mechanical properties in the incisive cuticle of mandibles of Porcellio scaber Latreille, 1804. J. Struct. Biol. 188, 1-15.

Ingall, E.D., Brandes, J.A., Diaz, J.M., de Jonge, M.D., Paterson, D., McNulty, I., Elliotte, W.C., Northrup, P. 2011. Phosphorus K-edge XANES spectroscopy of mineral Standards. J. Synchrotron Rad. 18, 189-197.

Inoue H, Ozaki N, Nagasawa H. 2001. Purification and structural determination of a phosphorylated peptide with anti-calcification and chitin-binding activities in the exoskeleton of the crayfish, Procambarus clarkii. Biosci. Biotechnol. Biochem. 65, 18401848.

Inoue H, Ohira T, Ozaki N, Nagasawa H. 2004. A novel calcium-binding peptide from the cuticle of the crayfish, Procambarus clarkii. Biochem. Biophys. Res. Commun. 318, 649654.

IUCN. (2012). IUCN Red List Categories and Criteria: Version 3.1. Second edition. Gland, Switzerland and Cambridge, UK.

Keen, J.N., Caceres, I., Eliopoulos, E.E., Zagalsky, P.F., Findlay, J.B.C. 1991. Complete sequence and model for the A2 subunit of the carotenoid pigment complex, crustacyanin. Eur. J. Biochem., 197, 407-417.

Khan, A.F., Awais, M., Khan, S.A, Tabassum, S., Chaudhry, A.A., Rehman, I.U. 2013. Raman spectroscopy of natural bone and synthetic apatites. Appl. Spectrosc. Rev. 48, 329-355.

Kim, B., Gautier, M., Rivard, C., Sanglar, C. Michel, P., Gourdon, R. 2015. Effect of aging on phosphorus speciation in surface deposit of a vertical flow constructed wetland. Environ. Sci. Technol. 49, 4903-4910.

Knoll, A. 2003. Biomineralization and evolutionary history. Rev. Mineral. Geochem. 54, 329356.

Kunkel, J.G. 2013. Modeling the Calcium and Phosphate Mineralization of American Lobster Cuticle. Can. J. Fish. Aquat. Sci. 70, 1601-1611.

Levi-Kalisman, Y., Raz, S., Weiner, S., Addadi, L., Sagi, I. 2002. Structural differences between biogenic amorphous calcium carbonate phases using X-ray absorption spectroscopy. Adv. Funct. Mater. 12, 43-48.

Liu, Y., Cui, Y., Guo, R. 2012a. Amphiphilic phosphoprotein-controlled formation of amorphous calcium carbonate with hierarchical superstructure. Langmuir, 28, 6097-6105.

Liu, Y., Cui, Y., Mao, H., Guo, R. 2012b. Calcium carbonate crystallization in the presence of casein. Cryst. Growth Des. 12, 4720-4726. 
Lowenstam, H.A. 1967. Lepidocrocite, an apatite mineral, and magnetite in teeth of chitons (Polyplacophora). Science 156, 1373-1375.

Lowenstam, H.A. 1972. Phosphatic hard tissues of marine invertebrates - their nature and mechanical function, and some fossil implications. Chem. Geol. 9, 153-166.

Lowenstam, H.A., Weiner, S. 1985. Transformation of amorphous calcium phosphate to crystalline dahllite in the radular teeth of chitons. Science 227, 51-53.

Lowenstam, H.A., Weiner, S. 1989. On biomineralization. Oxford University Press, London, UK.

Lowenstam, H.A., Weiner, S. 1992. Phosphatic shell plate of the barnacle Ibla (Cirripedia): A bone-like structure. Proc. Natl. Acad. Sci. USA 89, 10573-10577.

Luo, Y.-J., Takeuchi, T., Koyanagi, R., Yamada, L., Kanda, M., Khalturina, M., Fujie, M., Yamasaki, S., Endo, K., Satoh, N. 2015. The Lingula genome provides insights into brachiopod evolution and the origin of phosphate biomineralization. Nat. Commun. 6, 8301.

Luquet, G. 2012. Biomineralizations: insights and prospects from crustaceans. Zookeys 176, 103-121.

Luquet, G., Marin, F. 2004. Biomineralizations in crustaceans: storage strategies. C. R. Palevol 3, 515-534.

Luquet, G., Le Roy, N., Zanella-Cléon, I., Becchi, M., Bucarey, S., Fernandez, M.S., Arias, J.L., Guichard, N., Marie, B., Marin, F. 2009. Characterization of Crustacyanin-A2 Subunit as a component of the organic matrix of gastroliths from the crayfish Cherax quadricarinatus. Mater. Res. Soc. Symp. Proc.1187, 69-75.

Luquet, G., Fernandez, M.S., Badou, A., Guichard, N., Le Roy, N., Corneillat, M., Alcaraz, G., Arias, J.L. 2013. Comparative ultrastructure and carbohydrate composition of gastroliths from Astacidae, Cambaridae and Parastacidae freshwater crayfish (Crustacea, Decapoda). Biomolecules 3, 18-38.

Luquet, G., Dauphin, Y., Percot, A., Salomé, M., Ziegler, A., Fernandez, M.S., Arias, J.L. 2016. Calcium Deposits in the Crayfish, Cherax quadricarinatus: Microstructure versus elemental distribution. Microsc. Microanal. 22, 22-38.

Mann, S. 1988. Molecular recognition in biomineralization. Nature 332, 119-124.

Mann, S. 2001. Biomineralization: Principles and concepts in bioinorganic materials chemistry. Oxford Chemistry Masters, Vol. 5. Oxford University Press, London. 
Marin, F., Luquet, G. 2007. Unusually acidic proteins in biomineralization. in: Bäuerlein, E., Behrens, P., Epple , M. (Eds.). Handbook of Biomineralization, Vol. 1: The Biology of Biominerals Structure Formation. Wiley-VCH Verlag GmbH, Weinheim, pp. 273-290.

Mittal V., Matsko, N.B. 2012. Analytical imaging techniques for soft matter characterization. Springer Science and Business Media, New York.

Murdock, D.J., Donoghue, P.C. 2011. Evolutionary origins of animal skeletal biomineralization. Cells Tissues Organs 194, 98-102.

Mutvei, H. 1980. The nacreous layer in molluscan shells. in: Omori, M., Watabe, N. (Eds.). The Mechanisms of Biomineralization in Animals and Plants. Tokay University press, Tokyo, pp. 49-56.

Neues, F., Ziegler, A., Epple, M. 2007. The composition of the mineralized cuticle in marine and terrestrial isopods: A comparative study. Cryst. Eng. Comm. 9, 1245-1251.

Ravel, B., Newville, M. 2005. ATHENA, ARTEMIS, HEPHAESTUS: data analysis for Xray absorption spectroscopy using IFEFFIT. J. Synchrotron Rad. 12, 537-541.

Raz, S., Weiner, S., Addadi, L. 2000. Formation of high-magnesian calcites via an amorphous precursor phase: possible biological implications. Adv. Mater. 12, 38-42.

Raz, S., Hamilton, P.C., Wilt, F.H., Weiner, S., Addadi, L. 2003. The transient phase of amorphous calcium carbonate in sea urchin larval spicules: The involvement of proteins and magnesium ions in its formation and stabilization. Adv. Funct. Mater. 13, 480-486.

Reeder, R.J., Tang, Y., Schmidt, D.T., Kubista, L.M., Cowan, D.F., Philips, B.L. 2013. Characterization of structure in biogenic Amorphous Calcium Carbonate: Pair distribution function and Nuclear Magnetic Resonance studies of lobster gastrolith. Cryst. Growth Des. 13,1905-1914.

Reid, D.G., Mason, M.J., Benny, K.K. Chan, B.K.K., Duer, M.J. 2012. Characterization of the phosphatic mineral of the barnacle Ibla cumingi at atomic level by solid-state nuclear magnetic resonance: comparison with other phosphatic biominerals J. R. Soc. Interface 9, 1510-1516.

Rivard, C., Lanson, B., Cotte, M. 2015. Phosphorus speciation and micro-scale spatial distribution in North-American temperate agricultural soils from micro X-ray fluorescence and X-ray absorption near-edge spectroscopy. Plant Soil, 1-16.

Romano, P., Fabritius, H., Raabe, D. 2007. The exoskeleton of the lobster Homarus americanus as an example of a smart anisotropic biological material. Acta Biomater. 3, 301-309.

Rousseau, M., Meibom, A., Gèze, M., Bourrat, X., Angellier, M., Lopez, E. 2009. Dynamics 
of sheet nacre formation in bivalves. J. Struct. Biol. 165, 190-195.

Rudwick, M.J.S. 1970. Living and Fossil Brachiopods. Hutchinson University Library, London, UK.

Sato, A., Nagasaka, S., Fuhirata, K., Nagata, S., Arai, S., Saruwatari, K., Kogure, T., Sakuda, S., Nagasawa, H. 2011. Glycolytic intermediates induce amorphous calcium carbonate formation in crustaceans. Nat. Chem. Biol. 7, 197-199.

Sauer, G.R., Zunic, W.B., Durig, J.R., Wuthier, R.E. 1994. Fourier Transform Raman spectroscopy of synthetic and biogenic calcium phosphates. Calcif. Tissue Int. 54, 414420.

Shechter, A., Berman, A., Singer, A., Freiman, A., Grinstein, M., Erez, J., Aflalo, E.D., Sagi, A. 2008a. Reciprocal changes in calcification of the gastrolith and cuticle during the molt cycle of the red claw crayfish Cherax quadricarinatus. Biol Bull 214, 122-134.

Shechter, A., Glazer, L., Cheled, S., Mor, E., Weil, S., Berman, A., Bentov, S., Aflalo, E.D., Khalaila, I., Sagi, A. 2008b. A gastrolith protein serving a dual role in the formation of an amorphous mineral containing extracellular matrix. Proc. Natl. Acad. Sci. USA 105, $7129-7134$

Simkiss, K., Wilbur, K.M. 1989. Biomineralization: Cell Biology and Mineral Deposition. Academic Press, San Diego, CA.

Soejoko, D.S., Tjia, M.O. 2003. Infrared spectroscopy and X ray diffraction study on the morphological variations of carbonate and phosphate compounds in giant prawn (Macrobrachium rosenbergii) skeletons during its moulting period. J. Mater. Sci. 38, 2087-2093.

Solé, V.A., Papillon, E., Cotte, M., Walter, P., Susini, J. 2007. A multiplatform code for the analysis of energy-dispersive X-ray fluorescence spectra. Spectrochim. Acta B62, 63-68.

Sparkes, S., Greenaway, P. 1984. The haemolymph as a storage site for cuticular ions during premoult in the freshwater/land crab Holthuisana transversa. J. Exp. Biol. 113, 43-54.

Thormann, E., Mizuno, H., Jansson, K., Hedin, N., Fernandez, M.S., Arias, J.L, Rutland, M.W., Pai, R.K., Bergström, L. 2012. Embedded proteins and sacrificial bonds provide the strong adhesive properties of gastroliths. Nanoscale 4, 3910-3916.

Travis, D.F. 1955. The molting cycle of the spiny lobster, Panulirus argus latreille. II. Preecdysial histological and histochemical changes in the hepatopancreas and integumental tissues. Biol. Bull. 108, 88-112. 
Travis, D.F. 1960. The deposition of the skeletal structures in the Crustacea. I. The histology of the gastrolith skeletal tissue complex and the gastrolith in the crayfish, Orconectes (Cambarus) virilis Hagen - Decapoda. Biol. Bull. 118, 137-149.

Travis, D.F. 1963. Structural features of mineralization from tissue to macromolecular levels of organization in the decapod Crustacea. Ann. N. Y. Acad. Sci. 109, 177-245.

Urmos, J., Sharma, S.K., Mackenzie, F.T. 1991. Characterization of some biogenic carbonates with Raman spectroscopy. Am. Mineral. 76, 641-646.

Vijayan, K.K., Diwan, A.D. 1996. Fluctuations in Ca, Mg and P levels in the hemolymph, muscle, midgut gland and exoskeleton during the moult cycle of the Indian white prawn, Penaeus indicus (Decapoda: Penaeidae). Comp. Biochem. Physiol. 114A, 91-97.

Vittori, M., Rozman, A., Grdadolnik, J., Novak, U., Štrus, J. 2013. Mineral deposition in bacteria-filled and bacteria-free calcium bodies in the crustacean Hyloniscus riparius (Isopoda: Oniscidea). PLoS ONE 8, e58968.

Weaver, J.C., Milliron, G.W., Miserez, A., Evans-Lutterodt, K., Herrera, S., Gallana, I., Mershon, W.J., Swanson, B., Zavattieri, P., DiMasi, E., Kisailus, D. 2012. The Stomatopod Dactyl Club: A formidable damage-tolerant biological hammer. Science 336, 1275-1280.

Wehrmeister, U., Jacob, D.E., Soldati, A.L., Loges, N., Häger, T., Hofmeister, W. 2011. Amorphous, nanocrystalline and crystalline calcium carbonates in biological materials. J. Raman Spectr. 42, 926-935.

Weiner, S., Dove, P.M. 2003. An overview of biomineralization processes and the problem of the vital effect. Rev. Mineral. Geochem. 54, 1-29.

Williams, A., Cusack, M., Mackay, S. 1994. Collagenous chitinophosphatic shell of the brachiopod Lingula. Phil. Trans. R. Soc. Lond. B. 346, 223-266.

Williams, R.J.P. 1976. Calcium chemistry and its relation to biological function. Symp. Soc. Exp. Biol. 30, 1-17.

Yudkovski, Y., Glazer, L., Shechter, A., Reinhardt, R., Chalifa-Caspi, V., Sagi, A., Tom, M. 2010. Multi-transcript expression patterns in the gastrolith disk and the hypodermis of the crayfish Cherax quadricarinatus at premolt. Comp. Biochem. Physiol. D3, 171-177.

Zhang, F., Cai, W., Zhu, J., Sun, Z., Zhang, J. 2011. In situ Raman spectral mapping study on the microscale fibers in blue coral (Heliopora coerulea) skeletons. Anal. Chem. 83, 78707875 .

Ziegler, A. 2003. Variation of calcium deposition in terrestrial isopods. in: Sfenthourakis, S., de Araujo, P.B., Hornung, E., Schmalfuss, H., Taïti, S., Szlavecz, K. (Eds.). The Biology of 
Terrestrial Isopods. Koninklijke Brill NV, Leiden, vol. 2., pp. 299-309.

Ziegler, A., Miller, B. 1997. Ultrastructure of $\mathrm{CaCO}_{3}$ deposits of terrestrial isopods (Crustacea, Oniscidea). Zoomorphol. 117, 181-187.

Ziegler, A., Fabritius, H., Hagedorn, M. 2005. Microscopical and functional aspects of calciumtransport and deposition in terrestrial isopods. Micron 36, 137-153. 


\section{Figure Legends}

Fig. 1. Pair of gastroliths from Astacus astacus. (A) Convex side in contact with the stomach epithelium, (B) Flat side in contact with the stomach cuticle. (C) Half gastrolith showing a polished cross-section where a layered inner structure is visible. (D) Complete decalcification of a gastrolith showing the organic matrix framework. Blue color in A and B and orange color in $\mathrm{D}$ correspond to the presence of carotenoid pigments within the gastrolith. (A, B, C and D: Light Microscopy).

Fig. 2. Inner view of a gastrolith after fracture (A-D: FESEM micrographs; insert: light micrograph). Insert indicates two regions where observations were made showing two different organizations. (A.1 and A.2) Magnifications of an early storage A area showing regular layers of irregular granules more or less fused. (B.1) The late storage B region exhibits an alternation of zones of free granules and zones of larger fused granules. (B.2) Transition zone between a fused granules area, on the left, and a free granules area, on the right. (C.1) Dense area due to the fusion of granules (which appear flattened after fracturing). (C.2) Magnification of a C.1 zone showing that the larger granules result from the fusion of nanogranules (also shown in Figs. 2D.2 and 3F). (D.1-D.2) Magnifications of a free granules area showing a network of spherules of around 200-nm diameter connected by chitin-protein fibers (arrows). The area indicated by a white square in Fig. 2D.2 is shown magnified in Fig. $3 \mathrm{~F}$.

Fig. 3. AFM micrographs (A1 and G.1: height images; C, D, E, G.2: phase contrast images) and FESEM micrograph in $\mathrm{C}$, showing, on a cross-section, the nanogranular composition of the gastrolith in accordance with the presence of amorphous mineral. (A) View of parallel granular layers (dotted lines) in the more convex region of the gastrolith synthesized during the late storage period (late premolt). (B) Magnification of the area shown in the white rectangle in A.2. Irregular granules of different sizes are visible. (C) Medium region (intermediate storage period). (D) Region close to the flat side (storage in early premolt). A similar granular-based structure is present whatever the region considered. (E) Magnification of the area indicated by a white square in B. Arrows indicate the presence of nanofibers among the smaller nanogranules. (F) FESEM image corresponding to a magnification of the 
area indicated by a white square in Fig. 2D.2 Arrows point out thick protein-chitin fibers. (G) Granular region where the correspondence between granules visible on FESEM and AFM images is indicated by dotted circles: the $200 \mathrm{~nm}$-diameter spherules are composed of single granules of $50 \mathrm{~nm}$-mean diameters.

Fig. 4. EDX elemental maps showing the distribution of selected elements $\mathrm{O}, \mathrm{Ca}, \mathrm{Mg}, \mathrm{Si}, \mathrm{Sr}$, $\mathrm{P}$ on a gastrolith cross-section. An apparent heterogeneous distribution is visible, more particularly for $\mathrm{Mg}$ and P. P-rich layers are well visible on the flat side corresponding to the early calcium storage period. Two P-rich layers, at the limit of the intermediate region, are also rich in $\mathrm{Mg}$. Each elemental picture results from the juxtaposition of 4 images.

Fig. 5. (A) EDX elemental maps showing the $P$ distribution. The a-b line indicates the transect line along which EDX analyses have been performed. Two squares indicate areas corresponding to the EDX global spectra shown in C. (B) Molar ratios calculated for Ca, P, $\mathrm{Mg}, \mathrm{Sr}$ and $\mathrm{S}$ along the transect a-b. * points out two $\mathrm{Mg}$-rich regions related to the two $\mathrm{Mg}$ rich layers visible in Fg 4 (Mg map). (C) Spectra showing the relative concentration of different elements obtained from the two areas shown in $\mathrm{A}$. Only the $\mathrm{P}$ and $\mathrm{Mg}$ concentrations are variable from one area to the other.

Fig. 6. Raman maps performed on a gastrolith cross-section generated by calculating the ratios of the integrated intensities of two bands at around $956 \mathrm{~cm}^{-1}\left(\mathrm{v}_{1} \mathrm{PO}_{4}{ }^{3-}\right)$ and $1080 \mathrm{~cm}^{-1}$ $\left(v_{1} \mathrm{CO}_{3}^{2-}\right)$. Different areas corresponding to three periods of storage (inserts above) have been analyzed. Map (A): early storage period. Map (B): intermediate storage period. Map (C): late storage period.

Fig. 7. Raman spectra obtained for the $a, b$ and c spots indicated in the 3 different maps, A, B and $\mathrm{C}$ of Figure 6: a (blue spectra), b (red spectra), c (green spectra) for the 3 maps. On the right, magnification of the $900-1200 \mathrm{~cm}^{-1}$ region of the spectra shown on the left. The spectra $\mathrm{a}$ in maps $\mathrm{A}$ and $\mathrm{B}$ are indicative of amorphous calcium phosphate as the main mineral (ACP with a $956 / 58 \mathrm{~cm}^{-1}$ band value superior to the $1080 / 82 \mathrm{~cm}^{-1}$ band). The spectra $\mathrm{b}$ in maps $\mathrm{A}$ 
and B are typical of amorphous calcium carbonate (ACC) with the presence of ACP (stated by the band at $956 \mathrm{~cm}^{-1}$ ). The three spectra obtained from the map $\mathrm{C}$ are similar and composed mainly of ACC and, in a lesser extent, ACP. Bands with the symbol* are indicative of the presence of a carotenoid pigment.

Fig. 8. XANES spectra at the P K-edge obtained for standard phosphorylated samples. (A) Organic samples. 1: Phytic acid, 2. Casein, 3. Glucose 6-P. (B) Mineral samples. 4: Dibasic calcium phosphate, 5: Geological apatite, 6: Amorphous Calcium Phosphate, 7: Tricalcium phosphate. Distinctive characteristics between organic and mineral samples are surrounded by 2 oval forms.

Fig. 9. P K-edge XANES spectra of gastrolith organic matrices. (A and B) Soluble (SM1) and insoluble (IM1) matrices, respectively, from the same Cherax quadricarinatus gastrolith sample. (C) Insoluble matrix from the same C. quadricarinatus specimen than for SM1. (D) Soluble matrix from an Astacus astacus quadricarinatus gastrolith sample. In A, red curve: Linear combination fit of SM1 spectrum using casein, G-6P and phytic acid standards. Fit is obtained with $100 \%$ phosphorylation casein-type (Athena software package).

Fig. 10. A. XRF spectrum averaged over the XRF map in B. Elemental peaks deconvolution performed using PyMCA (Solé et al., 2007). B. XRF maps obtained for P, Mg and $\mathrm{Na}$ elements on a gastrolith cross-section showing a layered elemental distribution.

Fig. 11. (A) P XRF maps where the localization of the 14 spots analyzed with micro-XANES is indicated. On the left three areas are indicated, shown magnified on the right. (B) Diagram showing the results of the linear combination fits calculated for the 14 layers shown in A. A mix of P-mineral and P-organic molecules is always present. 
Fig. 12. Example of a fit performed for spot 13 and obtained with a linear combination of 58.2\% Amorphous Calcium Phosphate (ACP), 25.8\% Tricalcium Phosphate (TCP) and 16\% Casein. 


\section{ACCEPTED MANUSCRIPT}

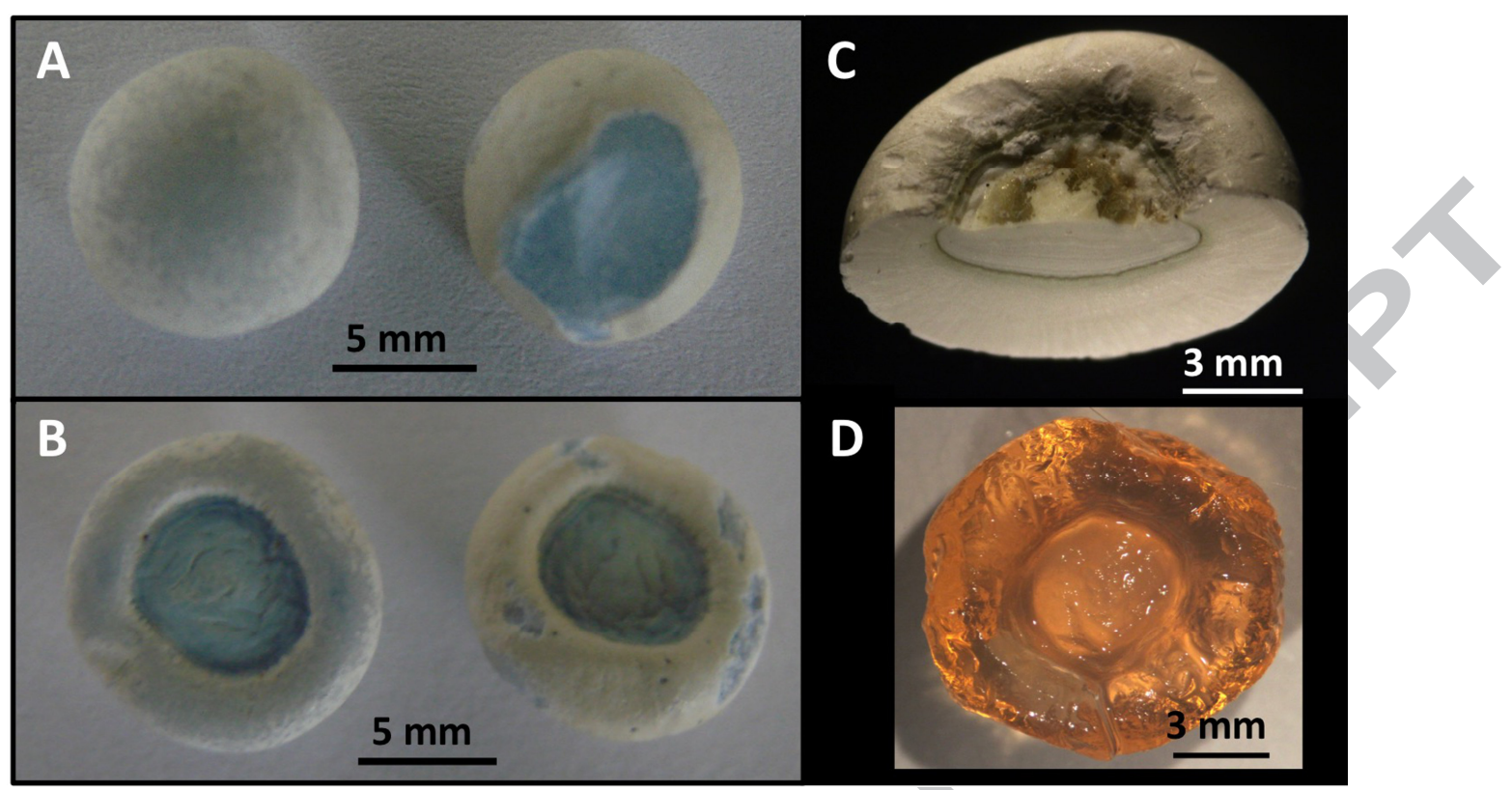

Fig. 1 


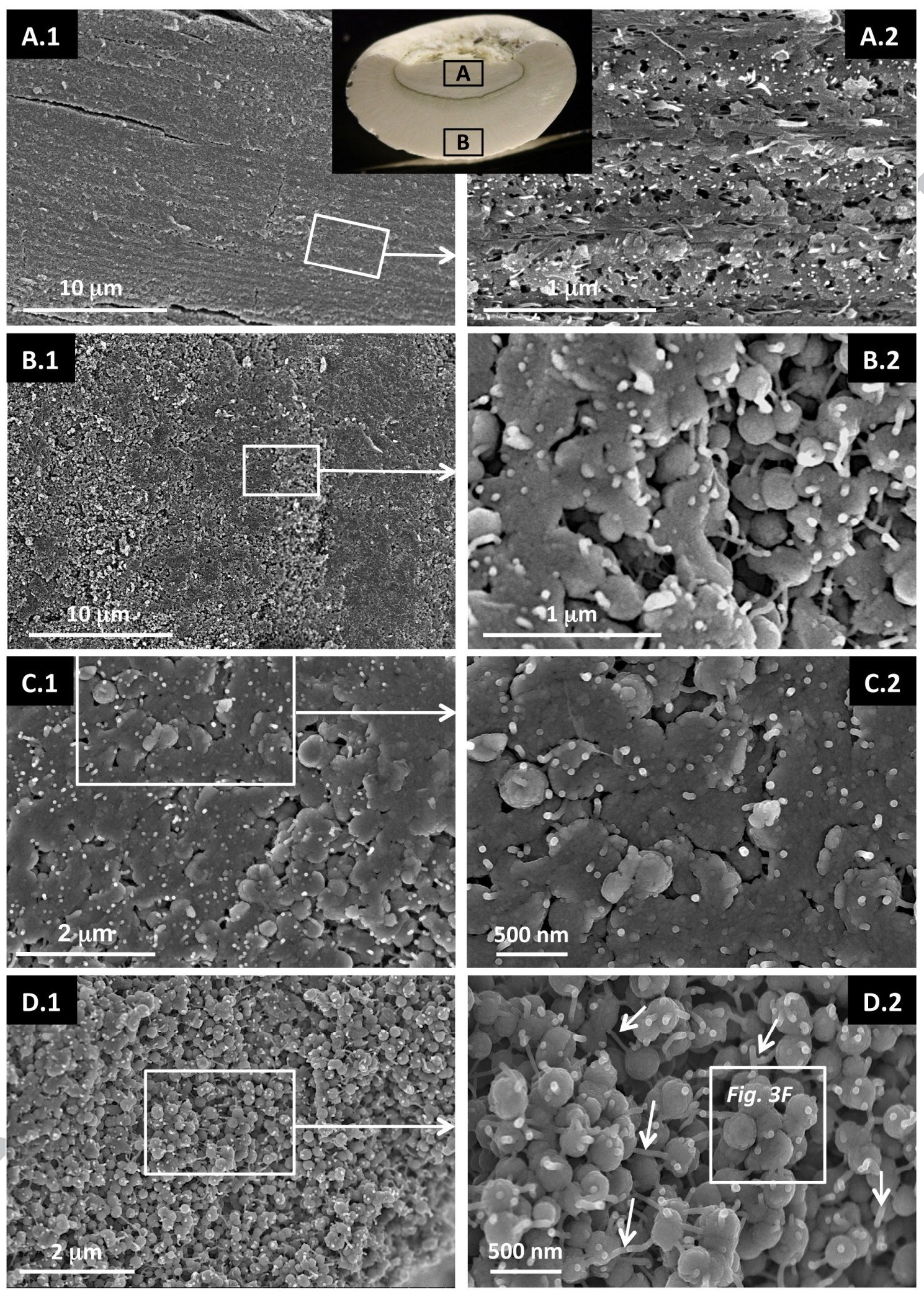

Fig. 2 

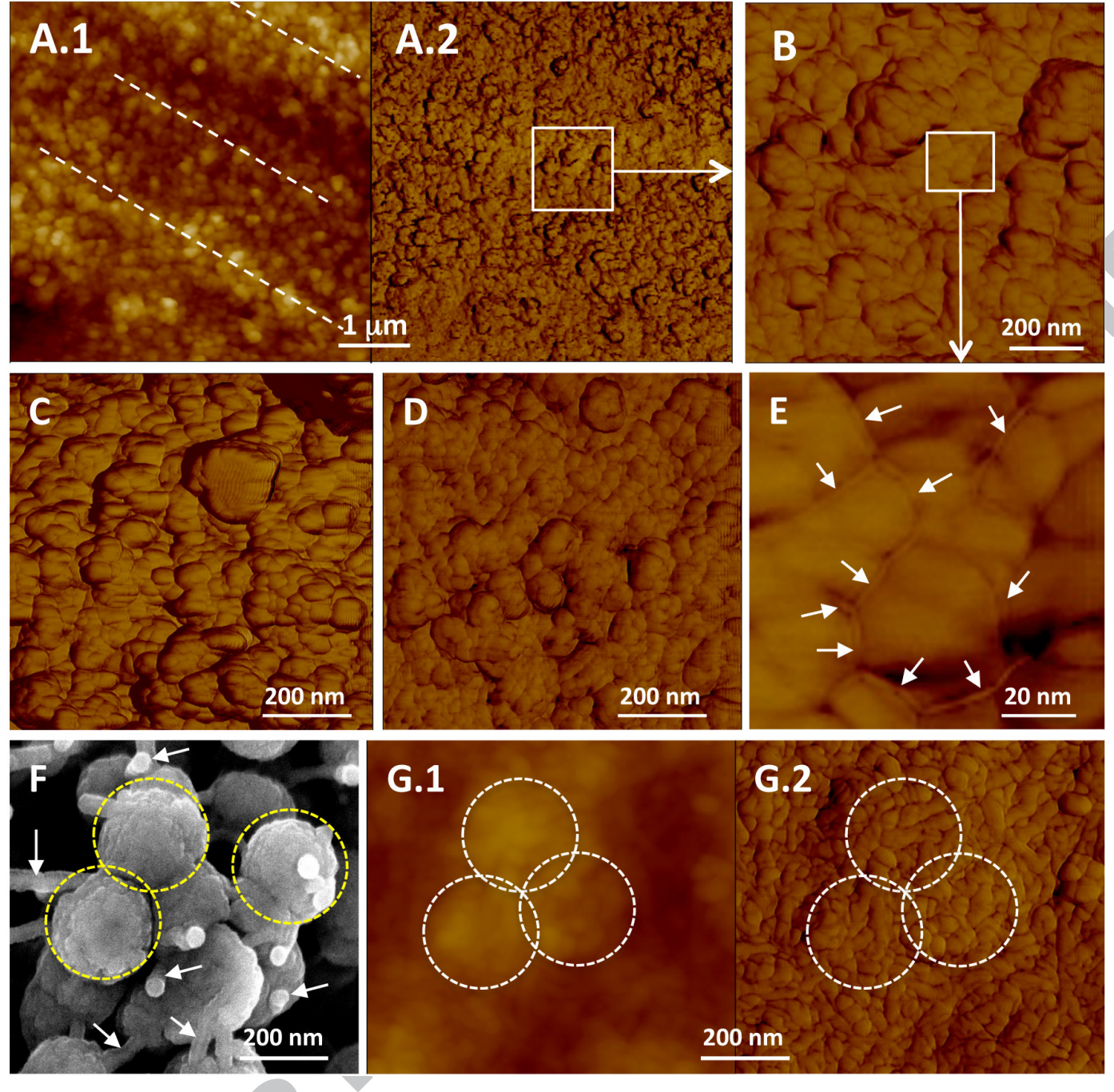

Fig. 3 

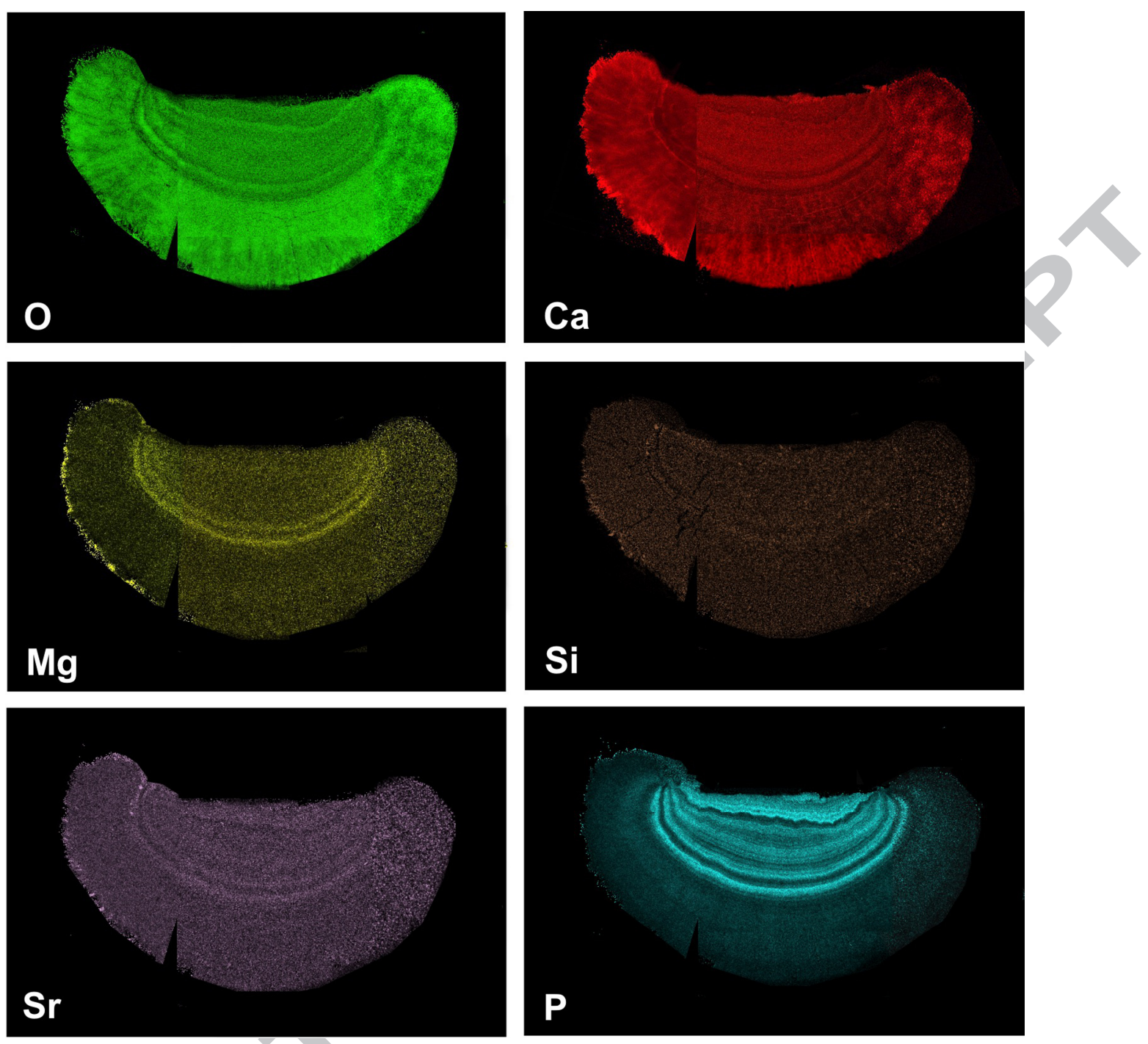

Fig. 4 


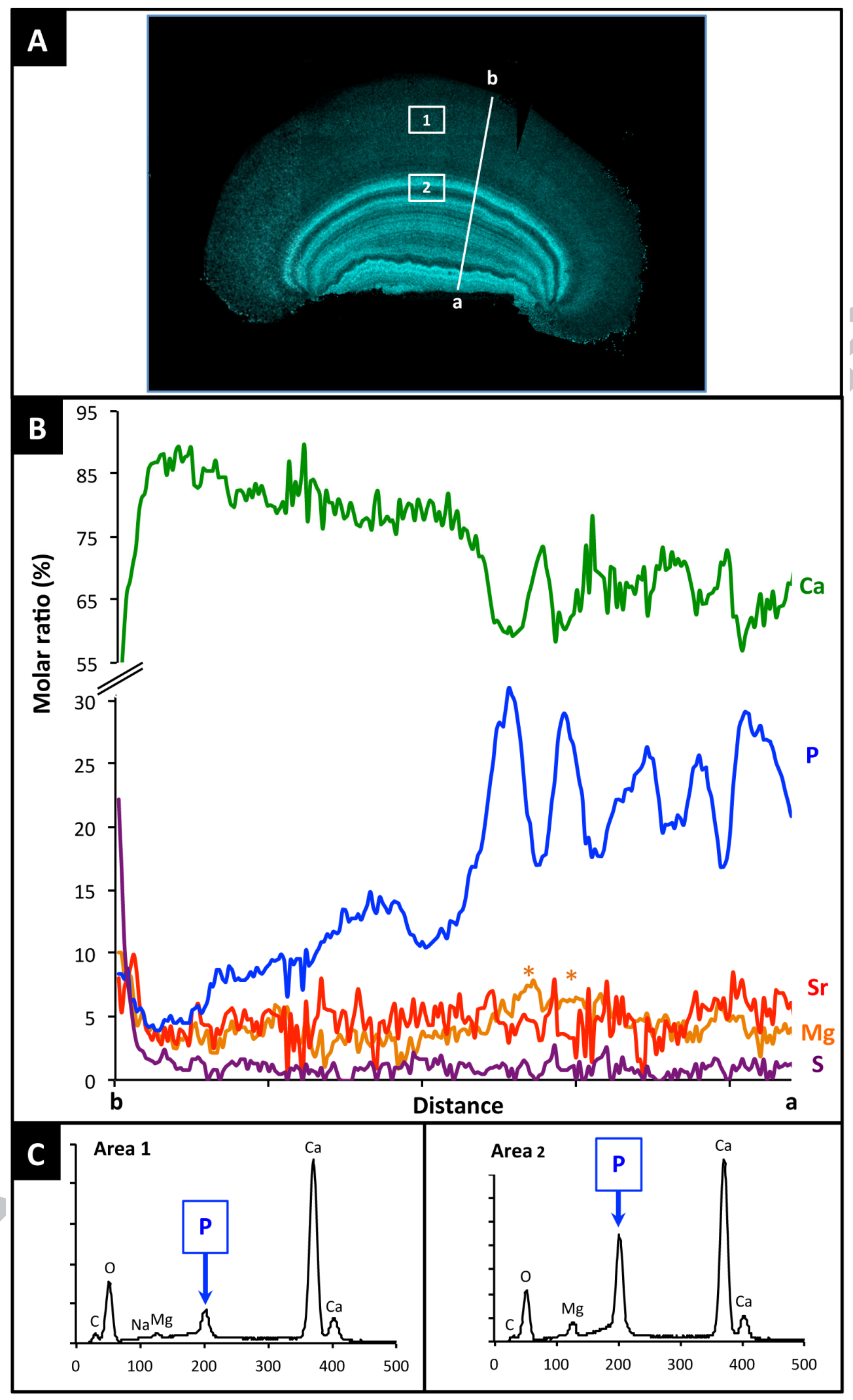

Fig. 5 


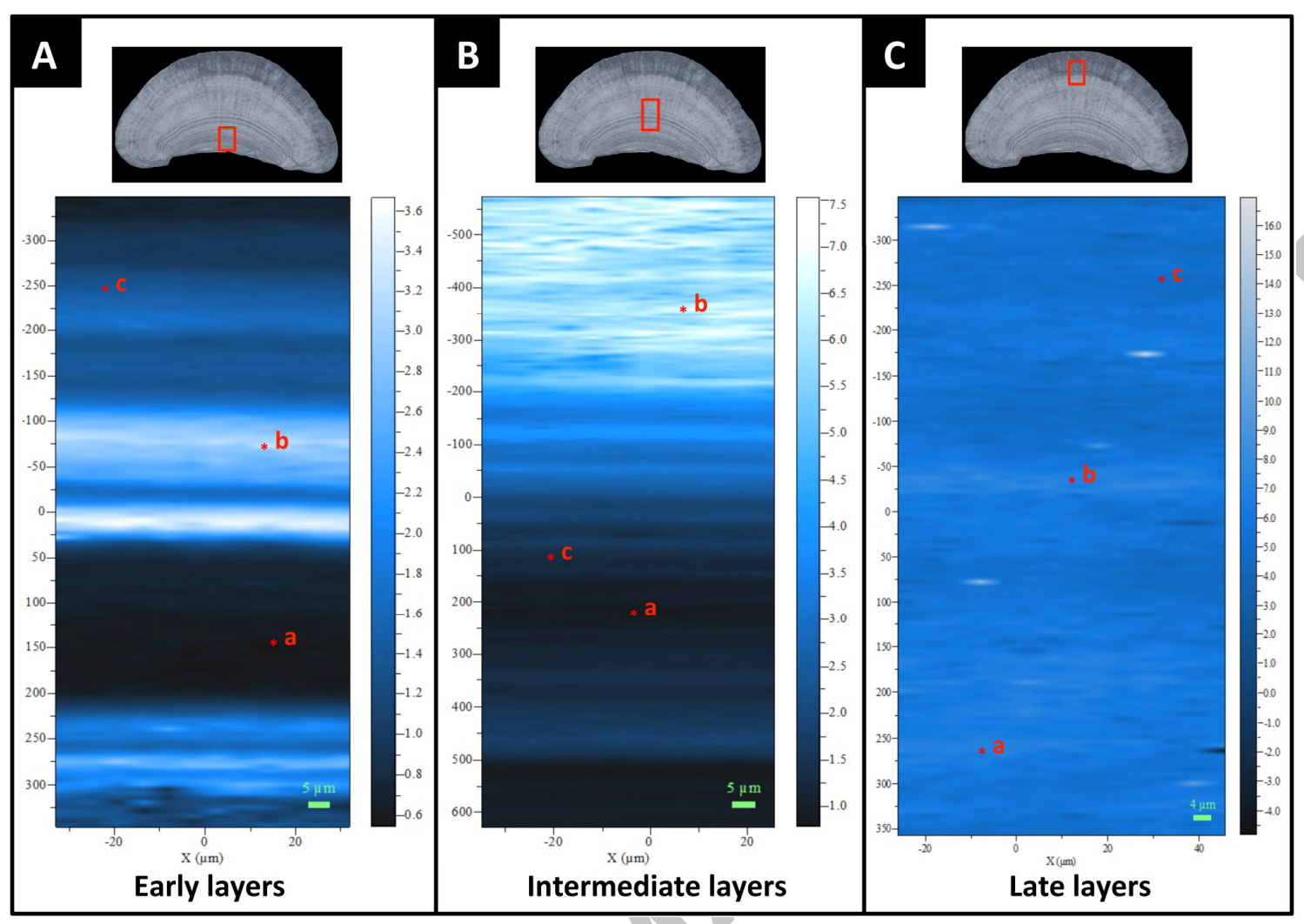

Fig. 6 

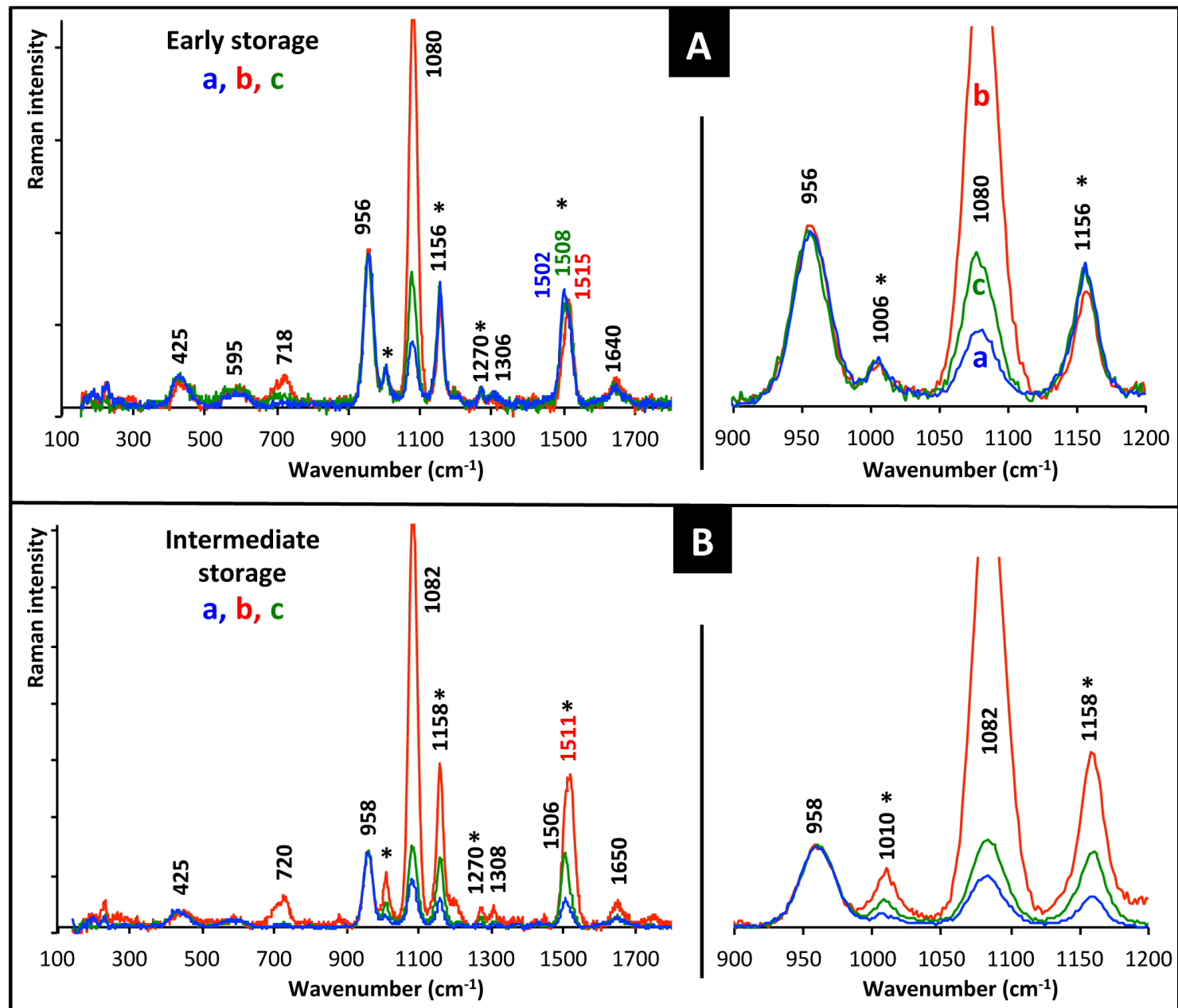

\section{B}
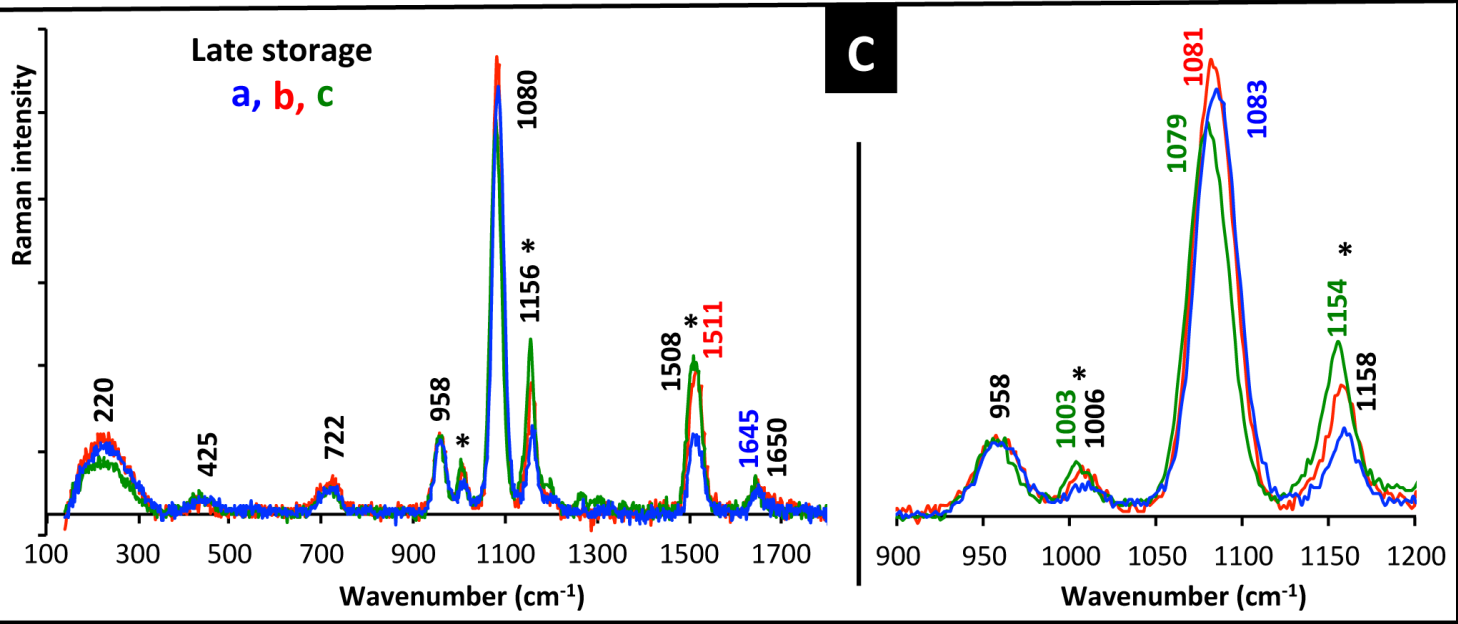

Fig. 7 

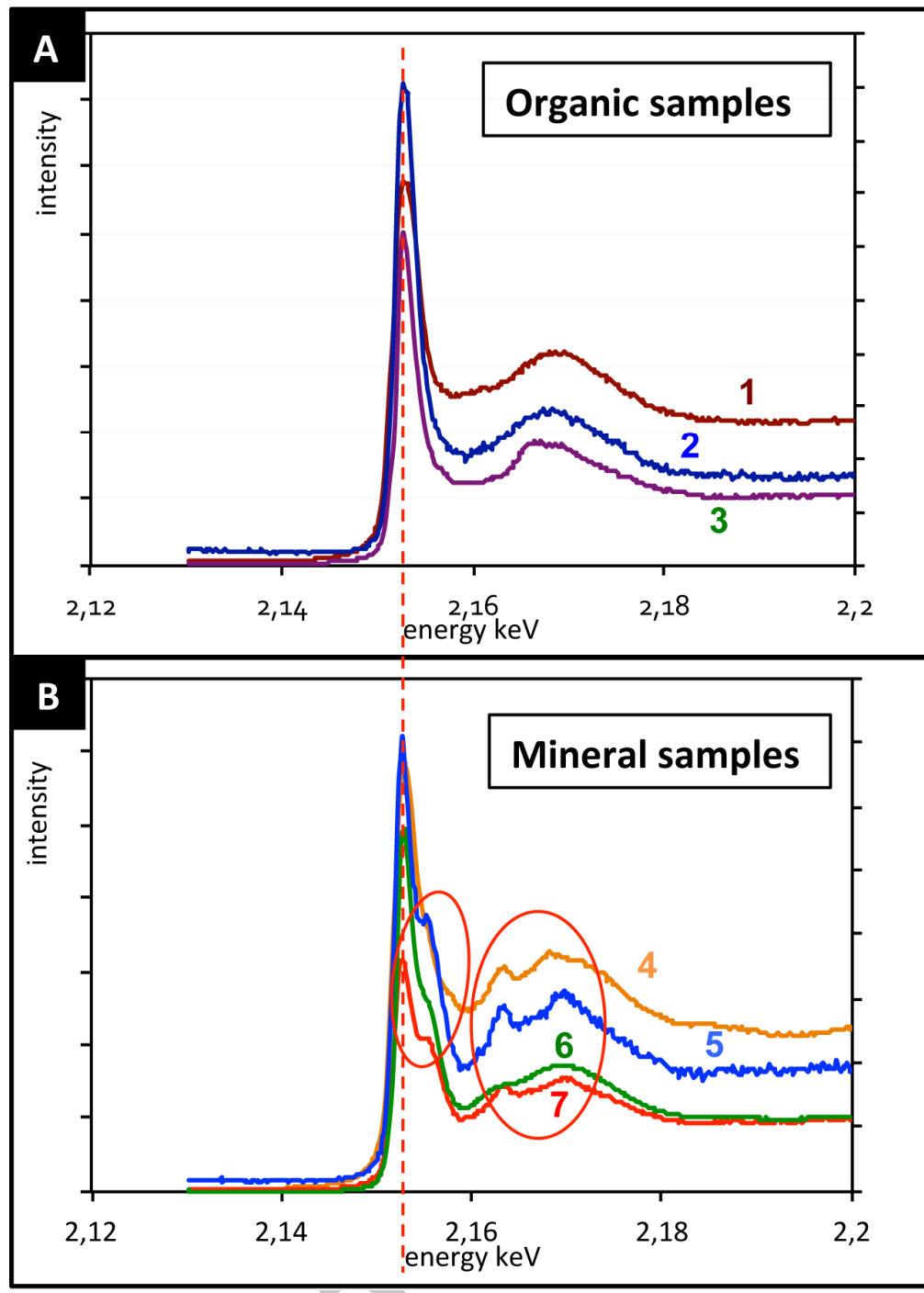

Fig. 8 


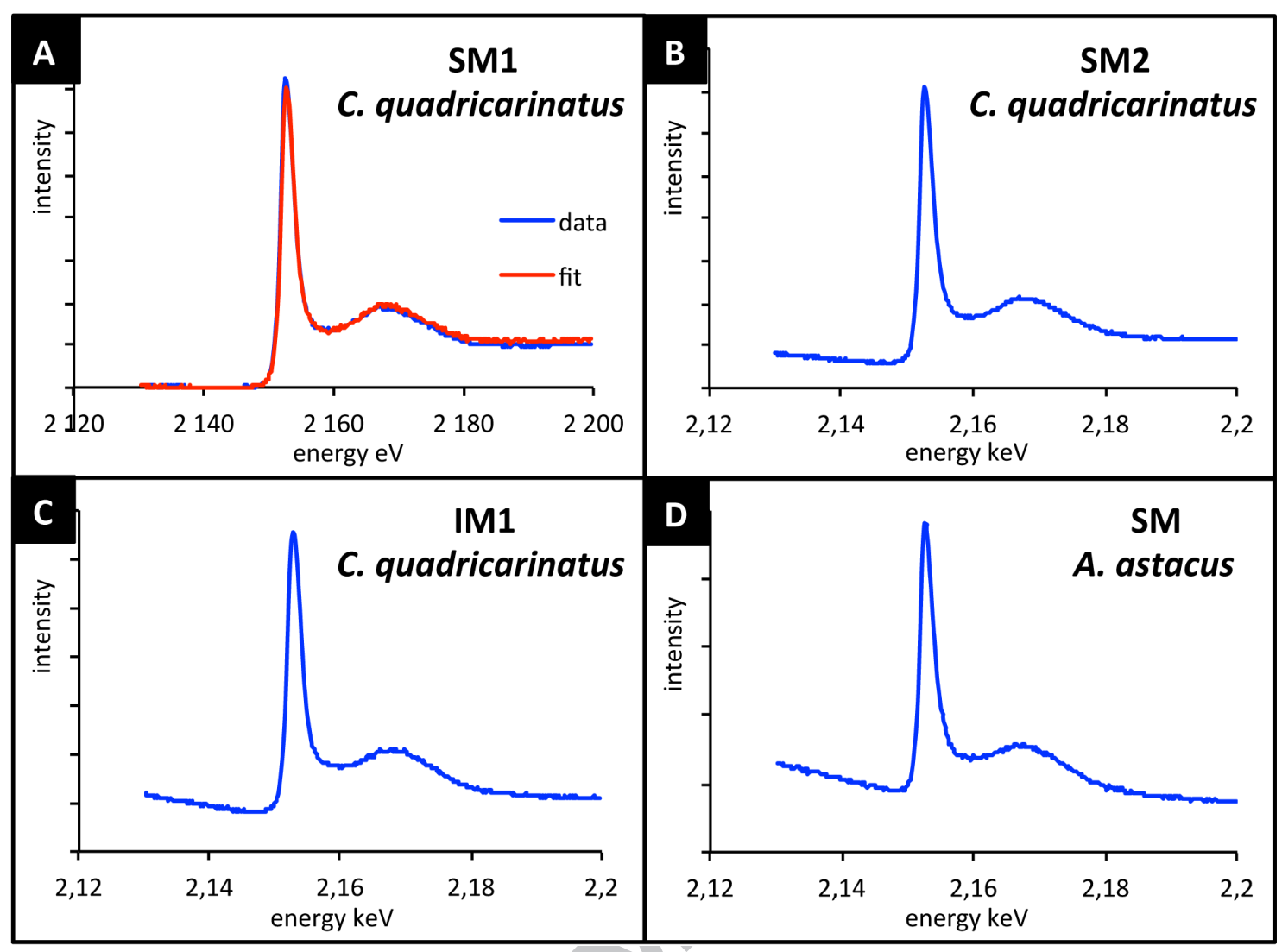

Fig. 9 


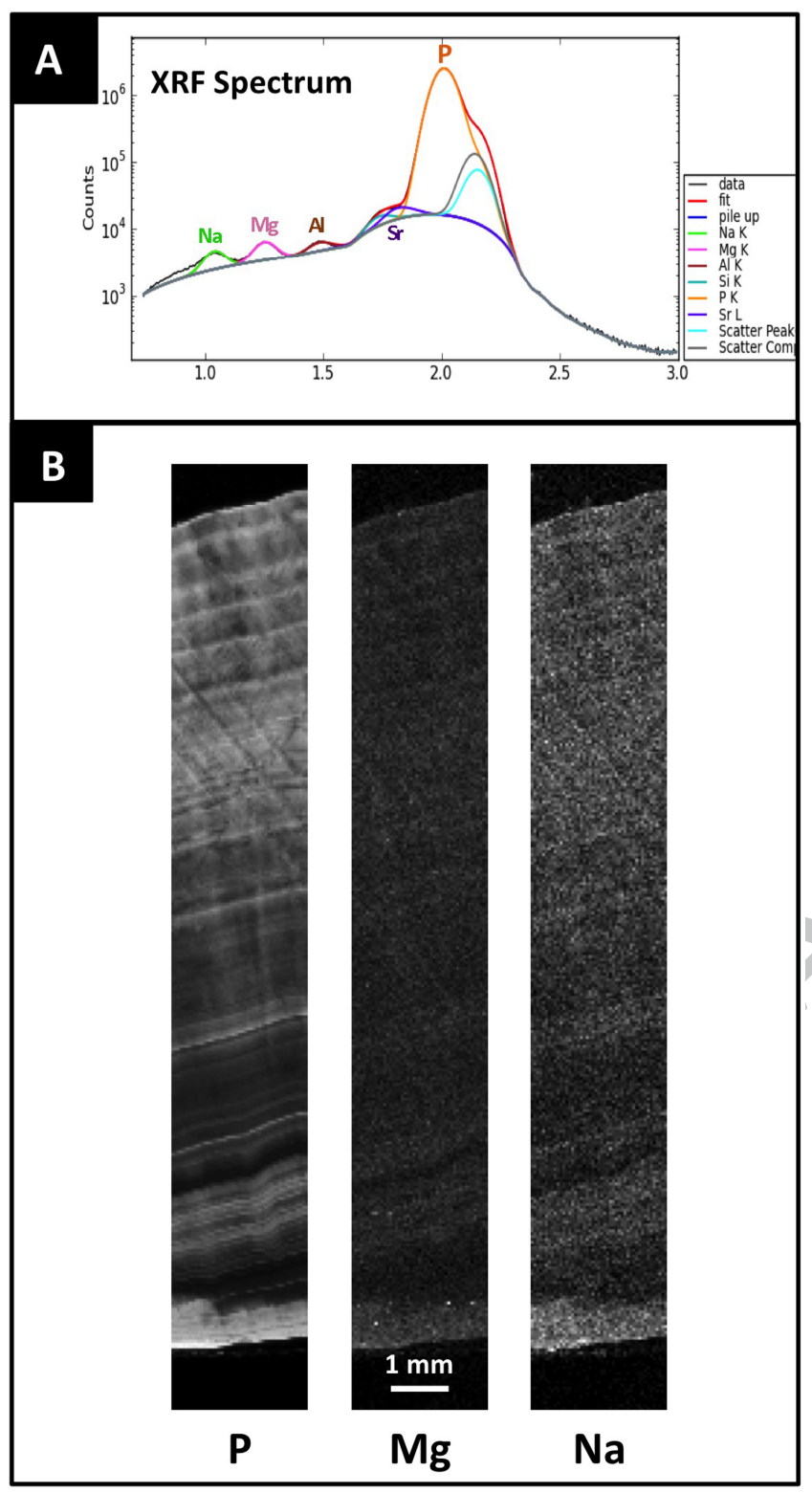

Fig. 10 


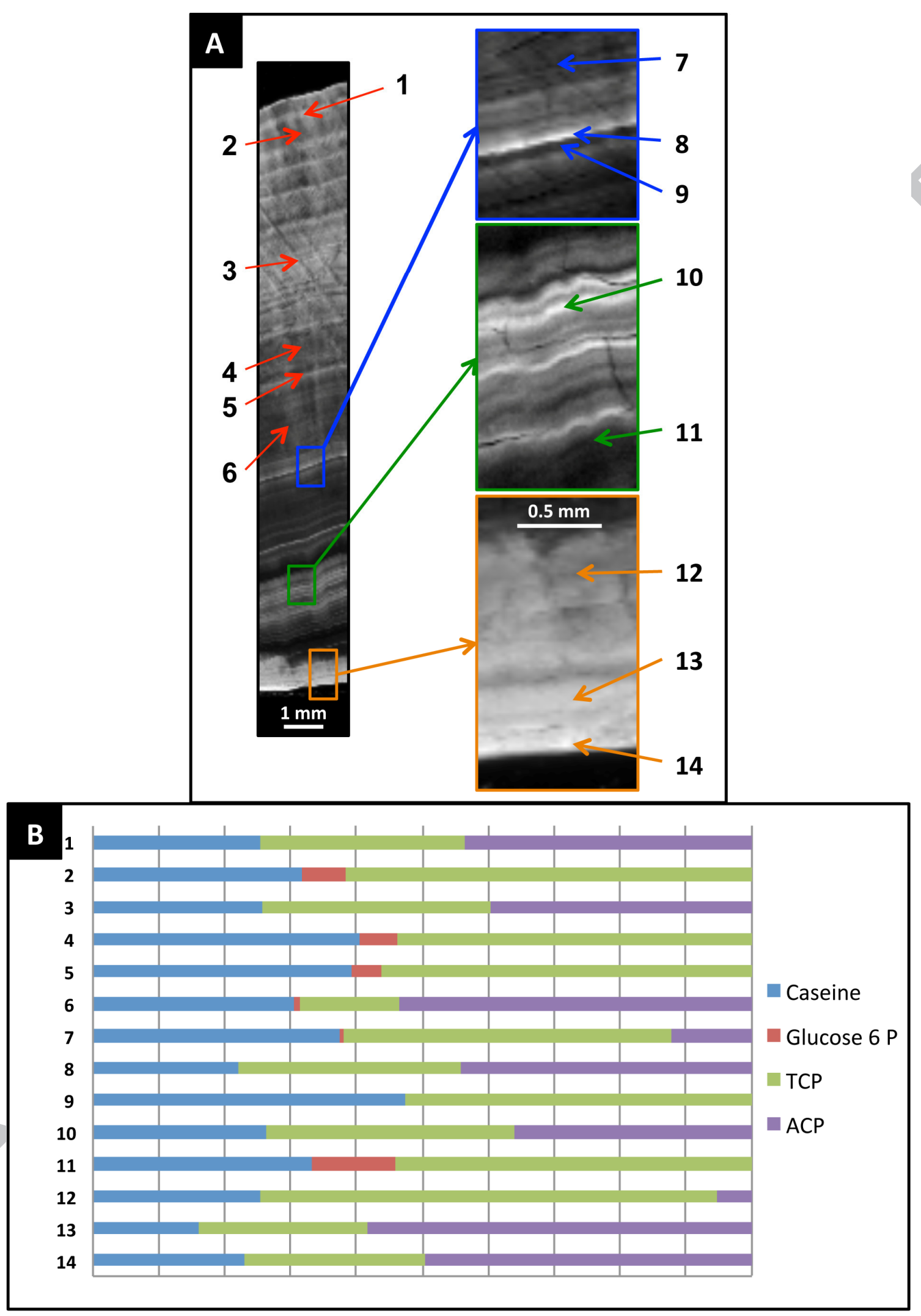

Fig. 11 


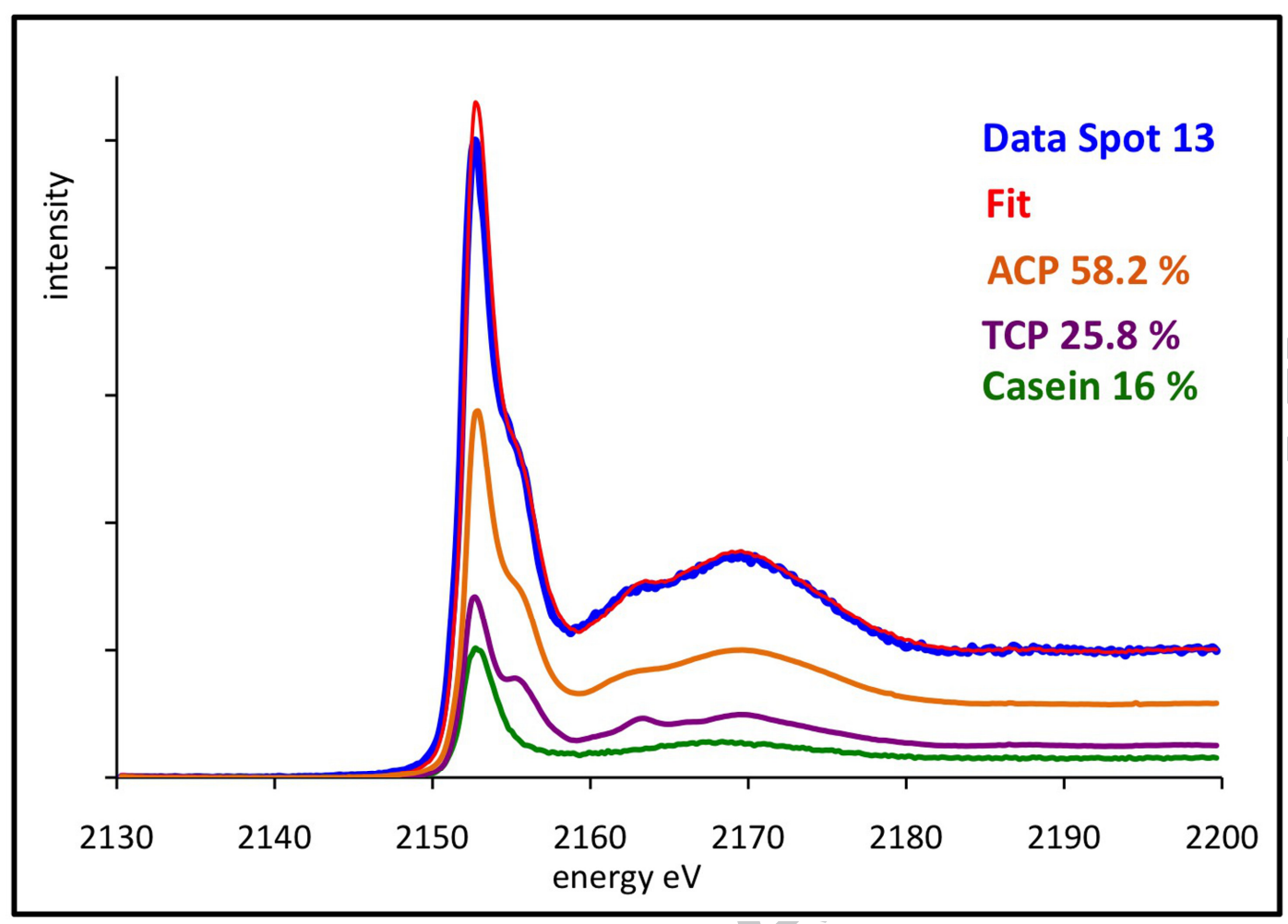

Fig. 12 